Portland State University

PDXScholar

\title{
A Study of the Narrative Skills of 7-Year Olds with Normal, Impaired, and Late Developing Language
}

\author{
Rita F. Hernandez \\ Portland State University
}

Follow this and additional works at: https://pdxscholar.library.pdx.edu/open_access_etds

Part of the Speech and Rhetorical Studies Commons

Let us know how access to this document benefits you.

\section{Recommended Citation}

Hernandez, Rita F., "A Study of the Narrative Skills of 7-Year Olds with Normal, Impaired, and Late Developing Language" (1996). Dissertations and Theses. Paper 5070.

https://doi.org/10.15760/etd.6946

This Thesis is brought to you for free and open access. It has been accepted for inclusion in Dissertations and Theses by an authorized administrator of PDXScholar. Please contact us if we can make this document more accessible: pdxscholar@pdx.edu. 


\section{THESIS APPROVAL}

The abstract and thesis of Rita F. Hernandez for the Master of Science in Speech Communication: Speech and Hearing Science were presented september 20, 1996, and accepted by the thesis committee and the department.

COMMITTEE APPROVALS :
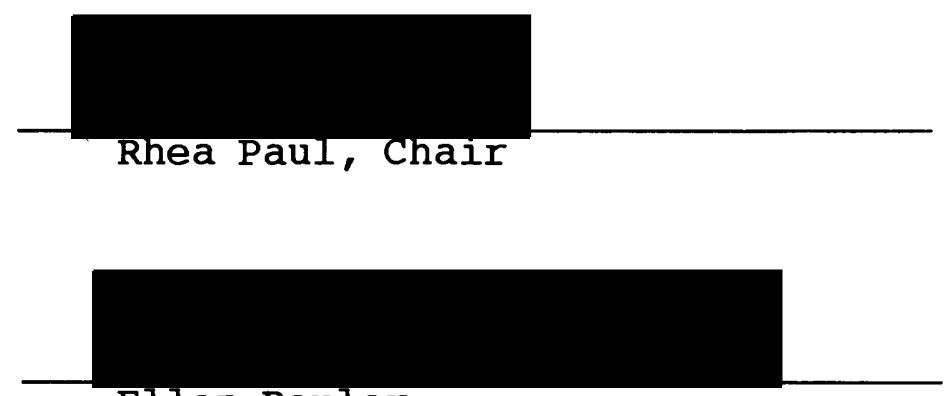

Ellen Reuler

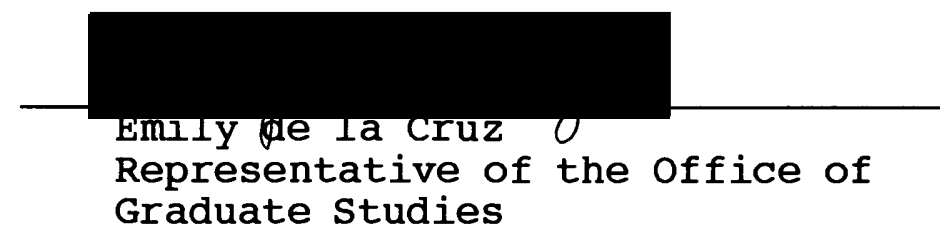

DEPARTMENT APPROVAL:

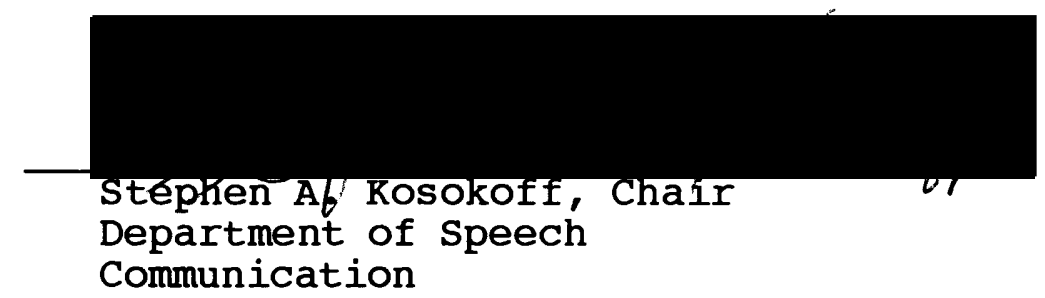

ACCEPTED FOR PORTLAND STATE UNIVERSITY BY THE LIBRARY

by on 30 Her 1996 


\section{ABSTRACT}

An abstract of the thesis of Rita F. Hernandez for the Master of Science in Speech Communication: Speech and Hearing Science presented September 20, 1996.

Title: A Study of the Narrative Skills of 7-Year olds With Normal, Impaired, and Late Developing Language.

The narrative, just like any lectured or monologue information which is shared, does not depend to any great extent on context. Therefore, ability to encode and decode the information to be presented verbally is required, that is, in order for the speaker to be able to verbalize what he or she wants to say while taking into consideration the listener's needs. This indicates that production of strong narratives depends on higher level language skills, and so children's narratives provide a sensitive means of assessing children's language development.

The purpose of this study was to compare the narrative ability of children at second grade age, using a wordless picture book, with differing rates of language development. Subjects were assigned to three diagnostic groups, (normal, history of expressive language delay, and chronic expressive language delay) based on their original diagnoses at 20 - 34 months (normal or late-talker) and 
their Developmental Sentence Score (Lee, 1974) at second grade age.

During the second grade assessment, each subject was audiotaped producing a spontaneous narrative using a wordless picture book. These narratives were scored on eight measures: Mean Length of Utterance per T-Unit, TypeToken Ratio, Narration Length in T-Units, Information, Average Sentence Length, Lexical Diversity, Cohesion, and Narrative Stage.

Results of the ANOVA and the Duncan Test multiple comparison procedures revealed significant differences among the groups on only one variable - Mean Length of Utterance per T-Unit. Children in the normal language group and the history of expressive language delay group performed significantly better than the group of children with chronic expressive language delay. No significant differences were found between the normal language group and the history of expressive language delay subjects. 


\section{A STUDY OF THE}

NARRATIVE SKILLS OF 7-YEAR OLDS WITH

NORMAL, IMPAIRED, AND LATE DEVELOPING LANGUAGE

by

RITA F . HERNANDEZ

A thesis submitted in partial fulfillment of the requirements for the degree of

MASTER OF SCIENCE

in

SPEECH COMMUNICATION :

SPEECH AND HEARING SCIENCE

Portland State University

1996 


\section{ACKNOWLEDGEMENTS}

I wish to extend my deepest gratitude and appreciation to Dr. Rhea Paul for her continual support and encouragement, as well as for the opportunity that she gave to me and the other research assistants who participated in the Portland Language Development Project.

Many thanks to Ellen Reuler and Emily de la Cruz for their participation on my thesis committee, and to Mary $\mathrm{T}$. Withers for being a great clinical supervisor.

I am grateful to all my friends who continued to believe in me and encouraged me throughout graduate school, especially G.J. Pincince, Toni R. Furano, and Debra Anderson. 
TABLE OF CONTENTS

PAGE

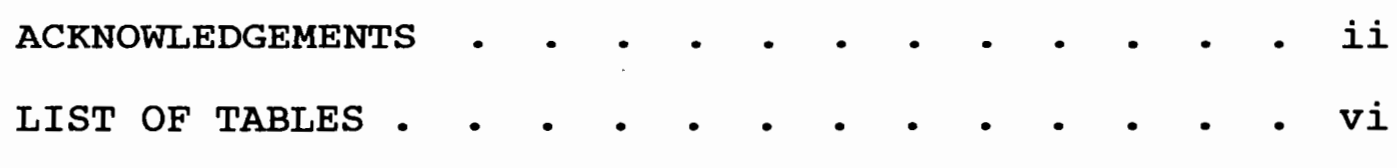

CHAPTER

I INTRODUCTION

Statement of Purpose • • • • • • 3

Definition of Terms • • • • • . 4

II REVIEW OF THE LITERATURE • • • • •

Narratives • • • • • • • • 8

Relationship between narratives

and academic success

Macrostructure of narratives

Cohesion

Narrative development

NARRATIVE DEVELOPMENT IN CHILDREN WITH LANGUAGE LEARNING DISORDERS • • • • • 14

Narrative structure in children with

language learning disability

Narrative structure in children with

reading disability

Cohesion in language learning disabled

children

Methodology and background for current study

SUMMARY

III

METHODS AND PROCEDURES • • • • • • 24

Subjects • • • • • • • • • • 
Recruitment

Subject description at intake:

$$
\text { age } 2
$$

Follow-up assessment: second grade

Criteria for language diagnostic group assignment: second grade

PROCEDURES

INSTRUMENTATION

- 31

Audiotaping

Developmental Sentence scoring

Narrative scoring

Reliability

ANALYSIS

Statistical analysis

IV

RESULTS AND DISCUSSION • • • • • • • 47

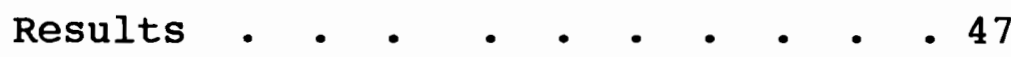

MLU per T-unit

DISCUSSION • • • • • • • • • • 52

V

SUMMARY AND IMPLICATIONS • • • • • . 56

Summary • • • • • • • • • 56

Implications • • • • • • • • 58

Research

Clinical

REFERENCES

APPENDICES

A HUMAN SUBJECTS RESEARCH FORM - • • • 70

B QUESTIONNAIRE FOR PARENTS OF CHILDREN

15 - 30 MONTHS OLD • • • • • 72

C OREGONIAN ARTICLE • • • • • • • • 74

D LANGUAGE DEVELOPMENT SURVEY • • • • • 76 
E DEVELOPMENTAL SENTENCE SCORE: SCORING CRITERIA

F DEVELOPMENTAL SENTENCE SCORE: NORMS • • 81

G NARRATIVE ANALYSIS CRITERIA - . . . . 83

H RULES FOR COUNTING T-UNITS AND WORDS • . 85

I 500 MOST COMMON WORDS USED BY

6-YEAR OLDS $•$ - • • • • • $\quad$ • 87

J COHESION SCORING PROCEDURE • • • • • .91

K INFORMATION SCORE CRITERIA - • . • • . 97 


\section{LIST OF TABLES}

TABLE

PAGE

I Group Demographic Information - • • - • 27 at Intake and Follow-up

II Group Description at Second Grade • • • 30

III Mean, Standard Deviation, and Range of - . 48 Each Group for Each of the Dependent Measures

IV ANOVA and Duncan Test Results • • • • . 50

V Kruskall-Wallace and Mann Whitney U . . . 51 Test Results 
CHAPTER 1

INTRODUCTION

There has been increased interest in recent years in analyzing children's narrative abilities as a measure of language skill. The narrative represents a series of events through the medium of a story which allows both the speaker and the listener to organize and interpret these experiences (Stephens, 1988). By school age, the stories children produce will rely on a story grammar format, providing information such as a setting, a problem, feelings of the involved characters, a struggle or attempt to overcome the problem, and a conclusion, again indicating the emotional response of the characters (Mandler, 1982). Since narratives children produce reflect their level of verbal skills, children's narratives are often used in research to measure a child's language ability. Starting at 2 years old children already have a story framework in place which becomes more complex or developed as verbal skills, cognition and social awareness increase with age (Applebee, 1978; Bernstein \& Tiegerman, 1989). Correlations have been shown to exist between early language delays (ELD) and poor performance in academics involving reading comprehension (Scarborough \& Dobrich, 1990). Since narrative text, which relies on higher level language 
skills, is the primary format used for conveying information in the elementary school years, narratives produced by young children can provide a strong indication of future academic success (Donahue, 1986; Feagans \& Applebaum, 1986; Roth \& Spekman, 1991). Studies of children's narratives show that children with slow language development at ages 4 - 6 display with delays in their narrative production (McFarland, 1992; Johnson, 1993). Other studies have shown that narratives produced by language disordered children of school age are shorter and present less mature use of episode, cohesion, and structure (Merrit \& Liles, 1987; Roth \& Spekman, 1986). Roth \& spekman (1989) have suggested the spontaneous story generation task to be a sensitive measure for assessing syntactic differences between normal and delayed subjects. Data based on a longitudinal study Feagans and Applebaum, (1986), proficiency in an oral narrative task as the most effective single linguistic predictor of success in academic activities. Therefore, because of the known connection between reading and academic success, these findings suggest that children with language disorders may be at risk for developing later reading problems and learning disabilities and that narratives produced from a story generation task are one area that can be analyzed to assess this relationship. 
STATEMENT OF PURPOSE

At home, at preschool and even kindergarten, children may rely on routines or other cues provided in the environment to give meaning to the language that they hear. But as the school years progress the information presented the classroom becomes more decontextualized. Studying children's narratives can give us insight as to what level a child's language skills have developed.

The purpose of this study is to examine narratives produced by second grade children involved with the Portland Language Development Project who presented with different language histories. The children were divided into three groups at age 7: 1. second grade children with normal language development (NL), 2. second graders with a history of language delay but currently adequate function (Hx), and 3. second graders with chronic expressive language delay (ELD). Of particular interest to this study will be whether significant differences will be present on eight measures of narrative skill in second graders that can be related to their pattern of language acquisition. It is expected that members of both groups with a history of delay will not perform as well on these tasks as the children in the normal group on narrative tasks which 
require use of higher order language abilities. The research hypothesis for this study is that on a story generation task, the skills of the second graders in the history of language delay and chronic expressive language delay groups will be significantly different from their normally developing peers. The null hypothesis is that in looking at three groups of second graders, i.e., the normal language development group, the expressive language delay group, and the history of language delay group, there will be no difference among the groups' narrative skills.

\section{DEFINITION OF TERMS}

Cohesion: Cohesion is a semantic system of ties that binds a text together (Nelson, in Nippold, 1988). Liles (1985) defines a cohesive marker as an element whose meaning cannot be interpreted without searching outside the sentence for the complete meaning. Cohesive markers are considered as complete ties if the information referred to by the cohesive marker is easily found, to be incomplete if the information is not provided immediately in the text, or if the listener receives ambiguous information.

Developmental Sentence Score (DSS) (Lee, 1974): A criteria for examining the adequacy of the grammatical structure of 
children's language, specifically the basic sentence. Only those utterances which formed complete sentences with a subject and predicate were used to process the DSS score.

Expressive Lanquage Delayed (ELD) Subjects: Those subjects who were late talkers at 20-34 months and at second grade scored 8.11 or below (10th percentile for age 6.6 ) on a language sample according Lee's (1974) DSS criteria.

History of Lanquage Delay (Hx) Subjects: Those children who were classified as late talkers at 20-34 months and at second grade received a score of 8.11 or above (10th percentile for age 6.6 ) on a spontaneous language sample according to DSS (Lee, 1974 ) criteria.

Information score: The information score refers to the total number of relevant pieces of information, the subject included in the narrative, according to criteria determined by McFarland (1992). One point is earned for each essential proposition used with a total of 26 possible points.

Late Talkers: The subjects were classified as late talkers if they used less than 50 different words at age 20-34 months by parent report on the LDS (Rescorla, 1989). 
Lexical Diversity: the number of unusual word types, used by the child in the narrative produced, is compared with the criterion of the 500 most common words used by 6-year olds on a list developed by Wepman and Hass.

Narrative Stage: Narrative stage assignments are determined according to procedures developed by Applebee (1978). Applebee (1978) categorized children's narratives into five stages: heap stories which are the least complex, followed by sequences, primitive narratives, chains, and finally true narratives which reflects the complex mature narrative. Each narrative sample will receive a numerical score from 1-5 with "1" representing the lowest stage, heap, and "5" representing the highest narrative stage, true narrative.

T-unit: The term T-unit is used to segment written or spoken discourse (Hunt, 1965). It contains one main clause plus any subordinate or non-clausal structures that are attached or embedded in it.

Text: Halliday \& Hasan (1976) describe text as any oral or written unit of language beyond the sentence level which forms a meaningful and unified whole. 
Type-Token Ratio (TTR): The Type-Token Ratio is computed by dividing the total number of words (tokens) into the total number of different words (types) (Miller, 1981). It is used to quantify general semantic aspects of a language sample. 
CHAPTER II

REVIEW OF THE LITERATURE

NARRATIVES

Relationship Between Narratives and Academic Success

"Discourse is the primary linguistic medium through which academic information is imparted and acquired" (Roth \& Spekman, 1991, p. 176). A narrative is a text which takes the form of a discourse in which the speaker presents in monologue form, extended units of text containing an introduction and an organized series of events which lead to a logical conclusion (Roth, 1986). Throughout the school years narratives are prominent in early reading and writing curricula and in oral language experiences like Show \& Tell (Scott, 1988). The language used in classrooms is different from that used at home. Language at home depends heavily on context, and children can act appropriately by following routines; understanding everything that is presented to them linguistically is not a necessity (Bernstein \& Tiegerman, 1989). In school, the language used has few contextual cues for children to rely on, and in early grades most information is presented to students through narrative texts. Westby (1985) claims 
that narratives may bridge a gap between the types of language used in the home and at school.

\section{Macrostructure of Narratives}

In 1977 Kinitch described narratives as having rigid culture-specific structures. For example, in its simplest form a narrative would include only one protagonist, with a series of events causally related to each other following. He described this story structure as the macro-structure of the narrative. Westby (1989) suggests that the reader or listener makes use of a schemata or story grammar, i.e., a stereotypical pattern according to which the events and goal-directed activities conform. This allows the reader or listener to follow the theme and construct coherence by relating stated ideas within each sentence to preceding and following sentences.

Montague, Graves, and Leavel (1991) describe seven aspects of a story grammar:

1. setting - when and where the story occurs and introduction of the main characters;

2. problem - an initiating event or problem that the main character must solve;

3. internal response - the main character's thoughts and feelings about the problem; his/her motivation to resolve the problem; 
4. attempt - action taken by the main character in order to solve the problem;

6. consequence - the result of the main character's attempt to solve the problem, which may be successful or unsuccessful;

7. reaction - how the character feels about the events which have occurred in the story; may be happy, sad, or confused.

\section{Cohesion}

Cohesion is one element that differentiates narratives from conversational discourse. Cohesion was described by Halliday \& Hasan (1976) as the use of certain grammatical structures in English which allow for the flow of meaning in a text, especially for reference to redundant information. They identified five kinds of cohesion processes: lexical cohesion, which involves semantic linking among vocabulary; grammatical cohesion which includes reference, substitution and ellipsis; and conjunction strategies (additive, temporal, adversative and causal) which link ideas (Nelson, cited in Nippold, 1988). As children grow older, their use and understanding of a greater number and variety of cohesive elements increases, along with expression of more and more complex relations in their narratives (Garnett, 1985). As children mature, 
their use of cohesion will progress from scanty, additive and temporally linked structures to complete, often embedded episodes, usually causally linked (Garnett, 1985). Previous studies of children's narratives have shown that language disordered children use fewer personal ties and a higher percentage of incomplete and error ties, as well as poorer use of cohesive conjunctives than normal language peers (Liles, 1985).

\section{Narrative Development}

Since a child's verbal skills and narratives progress in a parallel fashion, narratives are often used to measure a child's language ability. Narratives of older children reflect greater complexity by focusing on motivations, thoughts, and details, as well as consideration of the listener's needs in understanding causal-temporal factors. Bernstein and Tiegerman (1989) consider cognitive development and social awareness, which should increase with age, as primary contributors to the development pattern of children's narratives. Story structure patterns are evident in children beginning at age 2, and are continually developed and refined throughout the school years. Based on his studies of normally developing preschoolers aged 2 to 5, Applebee (1978) proposed six stages of narrative structure. 
a. Heap stories are usually a group of declarative sentences used for labeling or describing activities that may have no relation to each other; these are based on the child's immediate perceptions. Heap stories are considered a primitive mode of organizing the segments of a the story. In a study of 2-year olds by Pitcher and Prelinger (1963) only one-sixth of the children examined used heaps.

b. Sequences are the most commonly used narrative structure by 2-year olds. The sequence consists mainly of descriptions of the character's activities and the setting, but no plot is present. Associations between events may occur due to similarity rather than causal or temporal reasons .

c. Primitive narratives include a central character, object, or event. Cause-effect and temporal relationships among events are now evident, although an overall plot is not present.

d. Unfocused chain occurs when events are chained together and the defining attribute is continually shifting. No main theme, character, or plot are present.

e. Chain narratives center around concrete 
attributes, i.e., a main character experiences a series of events which are linked together temporally or by cause-effect reasons. The character's motivation is not clear at this time, and the ending does not lead to logical resolution. Applebee (1978) states that the chain accounts for over half the narratives of children at age five.

f. True narratives are marked by consistent forward movement beginning with situations which occurred at the primitive narrative stage which are now elaborated and clarified. The central theme, main character, and plot are now apparent with a logical resolution at the end. The most distinguishing aspect of the true narrative is that the character's motivations are now evident.

Children's language abilities are known to mature at different rates, so Applebee's six stages may not always appear at the same age for every child. But narratives produced by children can be assigned to one of these six stages depending on the organization and complexity of the structure used. 
NARRATIVE DEVELOPMENT IN CHILDREN WITH LANGUAGE AND LEARNING DISORDERS

\section{Narrative Structure in Children with Lanquage Learning}

\section{Disability}

Researchers consider the narrative to be a fertile database for the study of children's language because children must have acquired a variety of cognitive and linguistic skills in order to be able to tell or write narratives (Kelcan-Aker \& Kelty, 1990). Samples of children's narratives allow extended units of connected language to be examined (Roth \& Spekman, 1991). Some studies have reported no significant differences between narratives of language-impaired and normal children (Kelcan-Aker, 1985; Roth \& Spekman, 1989). But in general, it has been found that narratives produced by languageimpaired and language learning-disabled children are shorter, less mature, and present less mature episode and sentence structure than those of normal language peers (Roth \& Spekman, 1986; Merrit \& Liles, 1987). Similarities between the narratives of normal and language disordered peers consist of similar and unambiguous references, and both groups demonstrate concern for the listener's role. But, Liles (1985) points out that the language-impaired children show less efficient use of cohesion when compared 
to normal children. She attributes this deficiency of cohesion to be due to poorer narrative organization, i.e., use of fewer conjunctions, more ambiguous reference, and failure to consider the needs of the listener. In their study of 4 year olds, Paul \& Smith (1993) found that language delayed children had difficulties not only in formulating grammatical sentences, but also with "encoding, organizing and linking propositions, and in retrieving precise and diverse words from their lexicon" (p. 10). The same children from the Paul \& Smith (1993) study e were assessed again by McFarland (1992) at kindergarten age. Results showed significant differences between the normal group and the language delayed group in the areas of lexical diversity, cohesion, and narrative stage assignment. Her study indicated that nearly two-thirds of the children identified at age 20-34 months with delayed expressive language skills had at kindergarten age moved into the normal range for expressive language as measured by the DSS (Lee, 1974). MCFarland (1992) also noted that the normal language group performed better on the measure of lexical diversity indicating that the children with history of language delay and those with chronic expressive language delay used fewer unusual word types (words that do not appear on Wepman \& Hass' list of the most common words of 6-year olds) on a spontaneous narrative task. Cohesion 
scores for these kindergartners also showed that children with normal language development performed significantly better than those children with ELD on the cohesion score which measured the children's use of linguistic markers to adequately link ideas. Therefore, narratives produced by the ELD group would present inadequate information for the reader to gain full comprehension of the flow of the story. The normal language group also performed significantly better than the ELD group when measured for narrative stage which suggests that the narratives produced by the children in the normal language group demonstrated a higher level of maturity when presenting a story grammar through the medium of a spontaneous narrative.

Johnson (1993), whose study continued the evaluation of these children who participated in the Portland Language Development Project when they reached the first grade, reported that significant differences were found between the normal language group and the chronic expressive language delay group on two measures: narrative stage and average sentence length score. These findings suggest that in addition to a higher overall maturity level, the normal language children used more complex sentence structures than the children with persistent language delays. Another significant difference found in Johnson's (1993) study was between the history of language delay group and the 
children with continued expressive language delays. On the measure of average sentence length score, the history of language delay group scored significantly higher than the continued expressive language delay group, suggesting that more complex sentence structures were used by the children who had moved into the normal range of language development for their age.

Narrative Structure in Children with Reading Disability

In 1970, Fry, Johnson, and Muehl, and in 1977, Smiley, Worthen, Campione, and Brown (1977) reported that children who were poor readers used less complex linguistic patterns in story retelling tasks. Westby, Magart, and Van Dongen (1984) observed third, fourth, and fifth graders considered to be low in reading skills. They found that these children produced stories (from a poster picture) which were significantly less complex, and contained fewer elements of meaning in each narrative clause than those of grade-average readers (Roth, 1986). Another study by MCNamee and Harris-Schmidt (1985) reported that stories retold by learning disabled children between 5-9 years old received lower narrative stage scores based on the Applebee Scale, indicating less complex linking of actions with ideas (Roth and Spekman, 1986). On a fictional story telling task, Roth and Spekman (1986) found that learning 
disabled children told stories with a significantly smaller proportion of complete episodes and that the middle parts of the story were often omitted. These studies indicate that children with language learning deficits have difficulty producing structurally complex narratives and forming complete episodes.

In 1984, Levi, Musatti, Piredda, and Sechi investigated the story retelling abilities of three groups of children: dyslexic children, children with impaired reading abilities, and normal children (mean age was 9 years old). This study involved a story generation task using four picture cards and a story retelling task using the same stimulus. The normal children and those with low reading ability showed improvements between the first task (story generation) and the second task (story retelling) with increases in lexical diversity and narrative explicitness. Although the dyslexic children showed improvements in terms of narrative complexity and lexical diversity, little or no improvement in narrative explicitness was noted. The investigators concluded that these children were unable to grasp the deep narrative structure of the story as told by the examiner.

\section{Cohesion in Lanquage-Learning Disabled Children}

Normal and language-disordered children show similar 
patterns of cohesion, such as the use of conjunctions and unambiguous reference, and both groups are influenced by the listener's role. However, language-impaired children are less efficient in their use of cohesion as compared to normal children due to their poorer narrative organization (Liles, 1985). Language-disabled children use fewer conjunctions and exhibit more ambiguous reference, and often fail to consider the needs of their audience (Liles, $1987)$.

Another area of interest concerning narrative production is the adequacy of cohesion. In 1985, Liles created a procedure for the measurement of cohesion in children's narratives, based on the descriptions of cohesion in English as defined by Halliday and Hasan (1976). Liles used this procedure to measure cohesion on a story retelling task. She found that language disordered children ( 7.6 - 10.6 years old) showed differences in cohesive organization and cohesive adequacy, using fewer personal reference ties and more demonstrative and lexical ties than normal children. Also, the narratives of the language disordered children showed higher percentages of incomplete and error ties. In general, their use of cohesive conjunctives was poorer (Liles, 1985). Smith (1991) reported significant differences between the cohesion scores of children with normal language 
development and those children with delayed expressive language. When these children reached kindergarten age, Paul, Laz1o, \& MCFarland (1993) reported that normally developing kindergartners produced an average of $85 \%$ complete cohesive ties in narratives, while kindergarten children with language delays produced an average of about $60 \%$ complete cohesive ties. However, when Johnson (1992) evaluated this group of children at first grade, she found no significant differences in their cohesion scores. Her results indicate that on a story retelling task, children who were identified as late talkers at age 2, had caught up with their normally talking peers in terms of using an appropriate number of linguistic markers to adequately link ideas in a story.

Liles (1985) suggested story grammar knowledge and cohesion to be independent factors, but that comprehension of story grammar alone would not be sufficient for producing a coherent story. Paul, Lazlo, \& McFarland (1993) recommend that school aged children, who produce narratives with less than $70 \%$ cohesion, should be considered as presenting with difficulties in cohesive text production. These studies conclude that the two measures of story grammar knowledge and cohesion scores will be indicative of the school aged child's success with production and comprehension of narratives. 
Methodology and Background for Current Study

This study will replicate a study by McFarland (1992) . She followed many of the same subjects involved in the Portland Language Development Project to age 5 to examine the narrative skills on a story generation task of kindergarten children with three different patterns of language acquisition. Her data showed significant differences existed between the normal language group and the ELD group on the measures of lexical diversity, cohesion, and narrative stage assignments. However, no significant differences among the groups in the areas of MLU per T-unit, TTR, and information score were found. In terms of narrative stage assignment she mentions that although the ELD group did describe some temporal and causal relationships in the story, overall their narratives were lacking in development of plot with character motivation and story resolution.

Westby (1991) recommended using a wordless picture book for a story generation task in assessing students' ability to recognize and comprehend schema knowledge. She reports that in order to recognize schema knowledge, children must recognize what the characters are doing on the page, infer emotional experiences, and incorporate activities and relationships on two adjacent pages. Also, understanding of temporal sequences, physical and 
psychological cause-effect relationships, and plans and reactions of the characters are also essential. Westby (1991) went on to point out that if students can not tell an adequate story with a wordless picture book, then they will not be unable to produce a coherent story when no context is provided. Most school-based curricula is delivered to students in narrative form, so, adequate ability to retrieve and organize schematic knowledge is essential in the academic setting. Therefore, information on the skills of young children producing narratives from wordless picture books could provide an indication of future academic success or failure, as well as suggesting areas that could be boosted through language intervention.

\section{SUMMARY}

These studies indicate that language impaired children produce narratives that are shorter, provide less information, and use a less diverse vocabulary than children with normal language development. Early studies of children who present as "late talkers" as toddlers suggest that these children produce less mature narratives than peers with normal language history at ages $4-6$. The 
present study will investigate if significant differences between the three groups - normally developing language, history of language delay ( $\mathrm{Hx})$, and chronic expressive language delay (ELD) persist into the second grade. 
METHODS AND PROCEDURES

\section{SUBJECTS}

A total of 54 children participated in this study. These subjects were recruited at approximately age 2 to participate in the Portland Language Development Project, a longitudinal study of the characteristics of children with slow expressive language development. Approval was received from the Portland State University Human Subjects Research Review Committee for the procedures used in the Portland Language Development Project.

\section{Recruitment}

Three methods were used for recruitment:

1. Questionnaires through the offices of private physicians were circulated in the Portland Metropolitan area over a 5month period to the parents of children aged 16 to 24 months. Information was requested as to the child's expressive vocabulary size and willingness to participate in a language development study.

2. An ad in the local newspaper, The Oregonian, was displayed requesting the parents of children in the age range 16 to 24 months to contact the Portland Language 
Development Project if they would be interested in participation in this study.

3. A local radio station broadcasted a request for speechdelayed toddlers able to participate in this study. Parents who responded to the ad and radio broadcast then were requested to fill out a questionnaire.

Subject Description at Intake: Age 2

From 1988 to 1993 the children who took part in the Portland Language Development Project were seen on a yearly basis. As these two groups (normal language and latetalkers) of children grew older, various aspects of their language skills were examined. Some of the children who started out as "late-talkers" began to present scores which fell into the normal range for language development. Therefore, a third group was created to describe those children with a history of late developing language, but who at the time of the examination had moved into the normal range for their age group. The three groups, normal language (NL), chronic expressive language delay (ELD), and history of late developing language $(\mathrm{Hx})$, were compared each year. As each year progressed more children from the ELD group moved into the Hx group.

Children were considered as slow in expressive language development (SELD) if they produced fewer than 50 
words, or no two-word combinations according to parent report on the Language Development Survey (LDS) (Rescorla, 1989), a vocabulary checklist (see Appendix) at 20 to 34 months. A group of normally speaking children whose parents reported expressive vocabulary greater than 50 words on the LDS was matched to the SELD group for age, sex ratio, birth order and socioeconomic (SES) indicator; both groups fell at the middle to lower class level. (See Table I). The present study presents data from the follow-up of children when they were in the second grade, approximately five years after intake.

Follow-Up Assessment: Second Grade

In 1993, when the participants were in the second grade (aged 83-107 months), the following tests were administered by research assistants involved in the Portland Language Development Project:

Vineland Adaptive Behavior Scales (Sparrow, Balla, \& Cicchetti, 1984),

Draw-A-Man (Harris \& Goodenough, 1963), Test of Lanquage Development-Primary (TOLD-P) (Newcomer \& Hammill, 1988), Peabody Individual Achievement Test (PIAT) (Dunn \& Markwardt, 1970), McCarthy Scales of Children's Abilities (McCarthy, 1972), 
TABLE I

GROUP DEMOGRAPHIC INFORMATION

AT INTAKE AND FOLLOW-UP

\begin{tabular}{lccccccccccc}
\hline Group & $\mathrm{n}$ & \% Male & \multicolumn{2}{c}{ Intake } & Age & SES+ & \#Words & Follow-Up Age* \\
& & & & Mean SD & Mean SD & Mean SD & Mean SD \\
\hline Normal & 26 & 61.5 & 25.7 & 4.5 & 3.42 & 1.06 & 192.9 & 91.7 & 96.85 & 2.33 \\
LT & 30 & 73.3 & 24.6 & 3.6 & 3.60 & 0.77 & 22.7 & 21.2 & 96.10 & 2.71 \\
\hline
\end{tabular}

* in months

+ using Hollingshead's (1975) four factor scale of social position, on a scale from 1 to 5 , where 1 is the lowest and 5 is the highest SES rating. 
The Lindamood Auditory Conceptualization Test (LAC)

(Lindamood \& Lindamood, 1979), and a hearing a hearing screening at $20 \mathrm{~dB}$ (ASHA, 1985).

A spontaneous speech sample was audio recorded, transcribed, and scored for Developmental Sentence Score (DSS) (Lee, 1974).

\section{Criteria for Lanquage Diagnostic Group Assignment: Second}

\section{Grade}

Three groups were created on the basis of DSS scores at the second grade assessment and intake group placements. These three groups were defined as follows:

1. The subjects were considered to have normal language (NL) if they used more than 50 different words at age 20-34 months as reported by the parents on the $\underline{\mathrm{LDS}}$ and also scored 8.11 or above (10th percentile for age 6.6 ) on the DSS (Lee, 1974) at second grade, from the free speech sample.

2. The subjects were considered to have a history of expressive language delay ( $\mathrm{Hx}$ ) if they were identified as late talkers at age 20-34 months because they produced fewer than 50 words, but at second grade age scored 8.11 or above $(10$ th percentile for age 6.6) on the DSS (Lee, 1974) 
calculated from the free speech sample.

3. The subjects were considered to be expressive language delayed (ELD) if they were identified as late talkers at age 20-34 months because they produced fewer than 50 words, and also scored below 8.11 (10th percentile for age 6.6 ) on the DSS (Lee, 1974) at second grade, calculated from the free language sample. (See Table II).

\section{PROCEDURES}

During the second grade assessment, a spontaneous speech sample was recorded on audiotape while the child had a dialogue with the research assistant. Questions such as: "What are your hobbies? Tell me about your last vacation. What does your little brother/sister do that bugs you?" were asked by the research assistant to elicit speech from the child. The sample was then transcribed into the Systematic Analysis of Language Transcripts (SALT) computer program. The DSS procedure was applied to 50 noun-verb utterances of the language sample. Hand scoring was done by graduate students trained in DSS procedure.

For the narrative task, the wordless picture book, $\underline{A}$ Boy, A Dog, and A Frog (Meyer, 1967) was presented to each subject by an examiner. The examiner sat across from the child so that she could not see the pictures in the book. 
TABLE ॥

GROUP DESCRIPTION AT SECOND GRADE

\begin{tabular}{|c|c|c|c|c|c|c|c|c|}
\hline \multirow[t]{2}{*}{ Group } & \multirow[t]{2}{*}{$\underline{\mathrm{n}}$} & \multicolumn{2}{|l|}{ Age* $^{*}$} & \multirow[t]{2}{*}{$\%$ Male } & \multicolumn{2}{|l|}{ DSS } & \multicolumn{2}{|c|}{ DSS Range } \\
\hline & & Mean & $\underline{S D}$ & & Mean & $\underline{\mathrm{SD}}$ & Min & Max \\
\hline Normal & 26 & 96.85 & 2.33 & 61.5 & 10.57 & 1.97 & 8.16 & 15.74 \\
\hline$H X$ & 24 & 96.13 & 2.95 & 79.2 & 10.26 & 1.27 & 8.60 & 13.98 \\
\hline ELD & 4 & 95.75 & 1.50 & 50.0 & 7.10 & 0.39 & 6.84 & 7.68 \\
\hline
\end{tabular}

* in months 
The examiner asked the child to "Look at the pictures and tell me a story. Remember I can't see the pictures. Tell the story like you would if you were reading a book." Later, the recorded sample was transcribed onto the Systematic Analysis of Language Transcripts (SALT) Computer Program (Miller \& Chapman, 1985). This information was analyzed on the SALT for the variables concerned with this study.

INSTRUMENTATION

\section{Audiotaping}

The subjects' narrations of A Boy, A Dog, and A Frog (Meyer, 1967) and spontaneous language sample obtained at second grade age were audiotaped using a Sony Dictator/Transcriber BM-88, A sony Ecm-144 Electret condenser lavaliere microphone, and Sony DC-30 cassette tapes.

\section{Developmental Sentence Scoring}

The DSS (Lee, 1974) assesses children's syntactic and morphologic development. Utterances from the spontaneous language samples (obtained after the narrative task) containing a subject-predicate relationship were scored for 
constituents of eight grammatical categories according to Lee's (1974) criteria. Lee has established norms for the DSS results.

Normative data for the DSS (Lee, 1974) consists of a subject group containing two hundred normally developing white children between the ages of 2-0 and 6-11 years, with five boys and five girls at each three-month interval. All but three subjects were rated as middle class according to the seven-point warren scale for rating occupations (Warren, Meeker, \& Eells, 1949).

Validity for the DSS scoring procedure was demonstrated by the significant differences produced between age group by the overall scoring procedure as well as by each of its component grammatical categories and the Sentence Point category. Internal consistency of the DSS was evaluated with Cronbach's Coefficient Alpha Correlation Coefficients (Guilford, 1954), which provides a general measure of reliability based upon comparison of individual components or category variance to the variance of the entire instrument. High reliability coefficients were obtained on this measure at the five one-year age levels and throughout the 2-0 to 6-11 year age period.

To demonstrate internal consistency of the scoring procedure across subjects, a split-half reliability analysis was used. The odd and the even items were 
combined and then correlated along with the Spearman-Brown formula to estimate reliability coefficients. The reliability coefficient for the over-all DSS with two hundred subjects combined was 0.73 . This showed good stability on the scoring process within subjects on a $50-$ utterance sample.

Overall stability of the DSS procedure was shown by the results of studies of stimulus material differences, sentence sequence effects, temporal reliability, and interviewing-clinician differences. Consistent overall results were found when the DSS was administered with different stimulus materials, as well as when DSS samples were elicited by different interviewers across three age levels.

\section{Narrative Scoring}

In this study, narratives produced on a story generation task were examined. For the purpose of quantitative analysis of the narratives produced, certain variables were chosen to assess the level of comprehension and expressive abilities of the subjects. The variables that will be employed in this study are as follows:

1. MLU per T-unit - the total number of morphemes expressed per T-unit. The number of morphemes per T-unit gives a general indication of the child's level of 
structural development of productive language (Miller, 1981). MLT is calculated by the Systematic Analysis of Lanquage Transcripts (SALT), computer program (Miller \& Chapman, 1985) by entering the text of the child's language sample which has been divided by T-units. The SALT program then calculates the MLT for each narrative transcript.

2. Type-token ratio - semantic information achieved by dividing the total number of words [tokens] by the total number of different words [types] (Miller, 1981). The SALT program automatically calculates type-token ratio (TTR) for each narrative transcript.

3. Lexical diversity - as a measure of unusual types of words, the number of words used in the narrative that are not on the wepman Hass (1969) list of the 500 most common words used by 6-year olds, was computed. A special modification to the SALT computer program developed by Ann Nockerts (1991) calculated the total number of unusual word types, i.e., words which do not appear on the Wepman Hass (1969) list, from each of the narratives.

4. Narration length in T-units - the number of T-units per narrative was calculated by the examiner. First the utterances were segmented according to intonation contours, and then re-examined for further segmentation into T-units. New T-units that were a continuation of an utterance were coded [T] before the first of the new T-unit. This 
segmentation allowed computation of utterance length without undue influence from run-on sentences. The number of T-units produced provides information as to the overall length of the narrative.

5. Information score - the total number of points awarded for relevant pieces of information, as determined by McFarland (1992), expressed in the story generation task for A Boy, A Dog, and A Frog (Meyer, 1967). McFarland (1992) analyzed the picture book and noted 26 main propositions which contributed to the continuity of the story. To calculate the information score, the contents of each child's narrative is analyzed for the appearance of these 26 propositions. The total number of propositions used by each subject matching the established 26 relevant pieces of information as established by McFarland (1992) represents the information score. This measure reflects the semantic complexity of the story. One point is earned for each essential proposition used with a total of 26 possible points.

6. Average sentence length - the narratives for A Boy, A Dog, And A Frog (Meyer, 1967) were scored for length using criteria created by Renfrew (1977). These rules stipulate that the words AND, THEN, and WELL be deleted when they appear at the beginning of a sentence. Then the five longest sentences in morphemes are chosen. The 
morphemes are summed and divided by five to produce the average sentence length score.

7. Cohesion adequacy - cohesion was identified by Halliday and Hasan (1976) as markers (words) whose meaning must be drawn from previous utterances. They described five types of cohesive processes:

a. Lexical cohesion, which involves the linking of words semantically (The boy went to the lake. He wanted to catch a frog.); grammatical cohesion involving personal reference (he, mine, it, one), or demonstrative reference (this, that, then) referring to a precise referent;

b. Substitution, referring to a category rather than a precise referent and ellipsis;

c. Conjunction strategies which tie information together by use of additive conjunction (e.g., and); adversative conjunctions (e.g., but, though); causal conjunction (e.g., because), or temporal conjunctions (e.g, then).

d. Ellipsis, information that is unstated but understood when sought from utterances outside the sentence, either preceding or following. e. Substitution, elements such as ONE or SOME, referring to categories rather than precise referents. 
Each subject's narrative was coded for use of cohesion according to criteria created by Liles (1985) for identifying cohesive markers and judging cohesive adequacy (Appendix). The entire transcript was read and analyzed line by line by the examiner. Any words for whose meaning the reader must look outside the sentence was identified as a cohesive maker. If information which completed the meaning of the word was found within the sentence the word was not considered as a cohesive marker. If two or more conjunctions appeared within a sentence, only the more complex conjunction was scored, using Liles' hierarchy of complexity. In this system causal conjunctions are rated as most complex, followed by adversative, temporal, and additive. Initial ands were not counted as conjunctions. After circling all the cohesive elements in the narrative, the examiner transferred the information to a score sheet, recording the line number of the cohesive marker in the transcript, the cohesive marker, the line number and word to which the cohesive maker referred, and whether the tie was complete or incomplete. Complete ties were identified as those for which the information referred to by the cohesive marker was easily found. Incomplete ties were those cohesive markers for which the referent information was ambiguous or not provided in the text. The cohesive adequacy score was then calculated for each 
narrative by dividing the number of complete ties by the number of complete plus incomplete ties.

8. Narrative stage assignment - The child's knowledge of story structure begins in the preschool years and becomes more sophisticated during elementary school. Applebee (1978) identifies narratives into five stages which progress from simple to complex accordingly with age and language development.

A modification of Applebee's system based on KlekanAker (1985) and MCFarland (1992) was used to assign narrative stage. Five levels of narrative development, based on the above sources, were identified. Each narrative was assigned a rank from $1-5$, corresponding to one of these five stages as a rating of its overall level of maturity.

The examiner read each narrative in its entirety and made a global judgement as to whether it should be classified as a heap, sequence, primitive narrative, chain, or true narrative. A heap story consists of simple labeling or descriptions of activities without organization or flow of meaning. No heap stories were gathered in this study. The following is an example of a heap story collected in a study by McFarland (1992, p.32):

"Mercer went out his home. Then he go to the playground. Then he found a frog. Then he fell off the cliff. 
Then he dead.

And then Mercer called the ambulance, the he took him to the hospital.

The he go to the ...

The he $\mathrm{x} \times \mathrm{x}$.

Then he put his nose in his face.

Then his blood came out.

Then he fell down in the water.

Then he on the police headquarters top of the

tree.

Then he $\mathrm{x} \times$.

Then I fell down.

But I have stay in bed.

He mad at the friend Mitty.

He 'Go home sister.'

then he fell down the water.

Then he catched that frog.

Then he 'Blah.'

Then he got into the drap.

It's a bad guy.

Then he called the police.

Then he rested.

And then he goed in jail.

Then that's the jail.

And his sister is feeling sad.

Then he found a big rock.

Then he went home by hisself.

Then Mercer came back.

Then he surprise.

Then he walk home.

Then he eat lunch.

Then he hungry.

Then he frog is

Then his mama is mad.

Then Mercer 'Mercer.'

Then he happy."

A sequence story consists of a series of descriptions about a character's activities. No plot is evident and one event does not follow temporally or causally from the previous event. The following example is a sequence story collected in this study:

It's a frog!

I'm gonna get him, I'm gonna get him. 


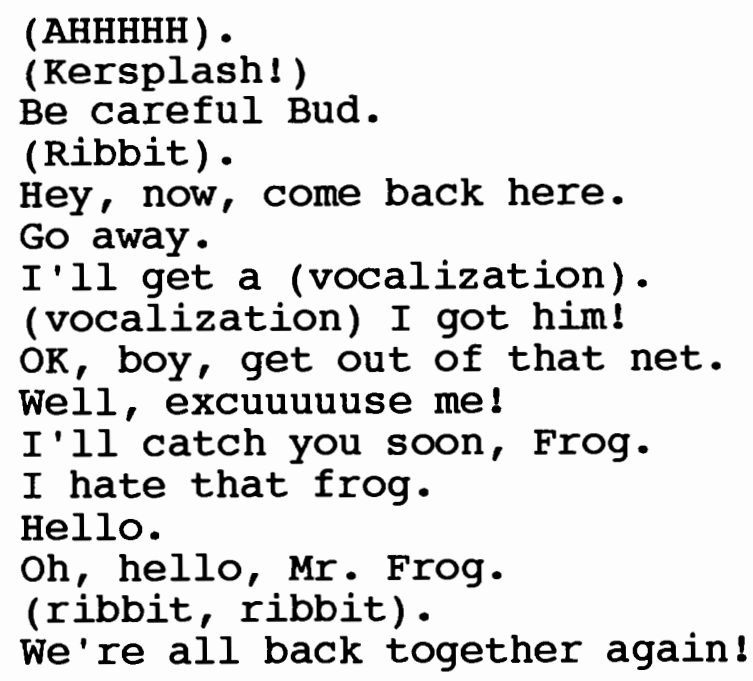

A primitive narrative presents a central person, object, or event. It contains three story grammar elements: an initiating event, attempt or action, and a consequence. No resolution to the story is evident, and character motivation is lacking. The following is an example of a primitive narrative collected in this study:

One day a boy wanted to go fishing.

He saw a frog in the pond.

He ran to catch it.

But he and his dog tripped and fell head first into the water. Then the frog jumped. The boy tried to catch it but he couldn't. so he climbed on a stick with his net and tried to get it.

But he missed.

He caught his dog instead. The frog ran and jumped on the log. Then the boy saw him. The boy and his dog walked away. They decide to go home. The frog was alone at the pond. The frog followed the footsteps all the way home into their living room.

He went up the stairs and into the bathroom. He jumped in the bathtub. 
The end.

A chain story contains some character motivation.

There is some evidence of cause/effect and temporal

linking, but may end abruptly without following a logical

series of events. Four story grammar elements may be

present such as an initiating event, attempt or action,

internal response, and consequence. The following chain

story was collected in this study:

One day a boy and his dog went to the pond.

And the boy saw a frog.

They ran down the hill.

They tripped on a stick.

The boy fell in the pond.

The dog did too.

The boy put his head up above the water and saw the frog.

And the dog was swimming.

The frog jumped onto the stick they tripped on.

The dog swam on one side of the stick.

And the boy climbed up on the other side of the stick.

The boy tried to catch the frog.

But instead he catched the dog.

He looked.

And he said, "I got him, I got him!"

But he looked up.

And he saw the dog.

And the boy said, "Oh, I'm mad!"

Then the boy walked away.

And the frog was sad.

The boy walked away with his net and his

bucket.

And his dog was weeping.

The frog was sad.

very sad.

The frog saw these footprints.

so he followed them.

And he goes, "Hmm, I wonder what's in here."

He followed the footprints.

And when he got in, he saw the boy and the dog. so the frog jumped in the bathtub. 
And then the frog jumped on the dog's head. The end.

Stories containing a central theme, elaborate character development, and a plot were identified as true narratives. These stories evidenced motivation behind the character's actions, logical and temporal sequencing of events, and at least five story grammar elements. The following is an example of a true narrative collected in this study:

A boy was in a tree looking at a pond. He went fishing.

He saw a frog.

He tried to catch the frog.

But he tripped and fell.

And he fell into the pond.

And when he came back up the frog was looking right at him.

He tried to get the frog.

But the frog jumped.

The boy was all wet.

He told the dog to go get the frog.

So they ganged up on him.

They were trying to get the frog.

But the frog jumped.

And the boy got the dog.

The frog was mad.

The dog was mad.

And the boy was mad.

And the frog became sad.

And the boy just left.

And he was mad.

And the dog just left.

And he was mad.

The frog was sad, by himself and lonely.

Then he saw the boy's and the dog's

footprints.

So he followed them home.

He was in the bathroom taking a bath.

And the frog was really happy to see him.

And he just jumped right in. 
And they made good friends.

Each narrative was assigned a numerical code from 1 to 5, 1 representing heap and 5 a true narrative.

\section{Reliability}

For language sample transcription reliability, $10 \%$ of the spontaneous language samples were randomly chosen and a second trained graduate student transcribed the middle 100 words from the audiotape. An average point-to-point agreement score of $90 \%$ was obtained by dividing the number of words in agreement for each transcript by 100 (McReynolds \& Kearns, 1983) and averaging the percent of agreement across transcripts.

For group assignments based on DSS scores, approximately $10 \%$ of the spontaneous language samples were randomly selected and another trained graduate student performed DSS independently. A point-to-point comparison was done for sentence scoring, dividing the total number of categorical points in agreement by the total number of categorical points in agreement plus disagreement, for each transcript. The average inter-rater reliability across the transcripts was 928 .

For narrative transcription reliability, $10 \%$ of the narrations were randomly selected and a second trained graduate student transcribed the entire narration from the 
audiotape. A point-to-point comparison was done on the utterances transcribed, and an agreement score of $97 \%$ was derived in the same manner as described above.

The narrative samples were scored by this researcher for the measures of narrative stage assignments, information score, occurrence of complete cohesion, and average sentence length. Using a sample of $10 \%$ of the total narratives, scores on each measure of narrative ability were arrived at independently by an additional trained researchers (directly involved with the longitudinal study), and inter-rater reliability was determined by percentage of agreement for each measure. Approximately $10 \%$ of the narrative samples were scored for reliability of the narrative stage assignment. Averaging the percent of agreement across the transcripts, yielded an inter-rater reliability score of $80 \%$. Approximately $10 \%$ of the narrative samples were scored for reliability of information scoring, dividing the total number of informational points in agreement by the total number of informational points in agreement and disagreement, yielding an inter-rater reliability score of 90\%. Approximately $20 \%$ of the narrative samples were scored for reliability of cohesion scoring, yielding an inter-rater reliability score of 89\%. Approximately $20 \%$ of the narratives were scored for reliability of average 
sentence length score, yielding an inter-rater reliability score of $90 \%$.

The mean length of T-unit ( $\mathrm{MLT}$ ), type-token ratio (TTR) and number of unusual word types are calculated automatically by the SALT computer program, and reliability measures were not computed.

\section{ANALYSIS}

The design to be implemented is a complex group design, with one independent variable, language diagnosis at three levels: normal language (NL), history of language delay (HX), and chronic expressive language delay (ELD) . The eight dependent variables which will be derived from the analyses of A Boy, A Dog, and A Frog, (Meyer, 1967), are : information score, average length of five longest sentences in morphemes, narrative stage assignment, percentage of correct cohesion used, mean length per T-unit in morphemes, number of T-units used in the story, number of unusual words produced, and type-token ratio. 


\section{Statistical Analysis}

For statistical analysis the data was assessed by measuring each group's mean, standard deviation, and range for each of the dependent variables. The following descriptive statistics were used to analyze the information: a one way analysis of variance, (ANOVA), on each of the narrative tasks to assess significant differences between the three language diagnostic groups; a post-hoc pair wise test, the Duncan Test was done for each ANOVA that was significant in order to determine where specific differences between the groups existed; and the Kruskal-Wallis Test and the Mann-Whitney U tests were used as a nonparametric analog of the ANOVA's. A nonparametric test was necessary due to the small sample size of the ELD group. 


\section{RESULTS AND DISCUSSION}

\section{RESULTS}

The specific objective of this study was to determine whether there are differences in spontaneous narrative ability (using a wordless picture book) in second grade children that can be related to history of SELD.

The research hypothesis was: on a story generation task, using a wordless picture book, the skills of the second graders in the history of language delay and chronic expressive language delay groups will be significantly different form their normally developing peers on the eight variables examined: story length in T-units, MUU per Tunit, TTR, average sentence length, information, lexical diversity, cohesion, and narrative stage.

The means and standard deviations of each group for each of the dependent measures were computed. These are shown in Table III.

The data were analyzed to determine whether significant differences existed between the language diagnostic groups of normal (NL), history of expressive language delay $(\mathrm{HX})$, and expressive language delayed (ELD) on measures of the spontaneous narrative task in order to 
TABLE III

MEAN, STANDARD DEVIATION, AND RANGE OF EACH GROUP FOR EACH OF THE DEPENDENT MEASURES

\begin{tabular}{|c|c|c|c|c|c|}
\hline \multirow[b]{2}{*}{ Measure } & \multirow[b]{2}{*}{ Group } & \multirow[b]{2}{*}{ Mean } & \multirow[b]{2}{*}{ SD } & \multicolumn{2}{|c|}{ Range } \\
\hline & & & & Minimum & Maximum \\
\hline \# T-Units & $\begin{array}{l}\mathrm{NL} \\
\mathrm{HX} \\
\text { ELD }\end{array}$ & $\begin{array}{l}30.0 \\
30.2 \\
31.2\end{array}$ & $\begin{array}{l}16.3 \\
10.9 \\
13.2\end{array}$ & $\begin{array}{r}6 \\
16 \\
18\end{array}$ & $\begin{array}{l}85 \\
65 \\
49\end{array}$ \\
\hline MLU/T-UNIT & $\begin{array}{l}\mathrm{NL} \\
\mathrm{HX} \\
\text { ELD }\end{array}$ & $\begin{array}{l}8.3 \\
7.9 \\
6.2\end{array}$ & $\begin{array}{l}1.3 \\
1.3 \\
1.0\end{array}$ & $\begin{array}{l}5.8 \\
5.6 \\
5.1\end{array}$ & $\begin{array}{r}11.0 \\
11.9 \\
7.5\end{array}$ \\
\hline TTR & $\begin{array}{l}\mathrm{NL} \\
\mathrm{Hx} \\
\mathrm{ELD}\end{array}$ & $\begin{array}{l}0.38 \\
0.36 \\
0.34\end{array}$ & $\begin{array}{l}0.07 \\
0.04 \\
0.07\end{array}$ & $\begin{array}{l}0.22 \\
0.28 \\
0.24\end{array}$ & $\begin{array}{l}0.55 \\
0.44 \\
0.40\end{array}$ \\
\hline ASLS & $\begin{array}{l}\mathrm{NL} \\
\mathrm{Hx} \\
\text { ELD }\end{array}$ & $\begin{array}{l}14.5 \\
15.1 \\
10.5\end{array}$ & $\begin{array}{l}3.3 \\
8.8 \\
2.5\end{array}$ & $\begin{array}{l}8.4 \\
8.4 \\
7.4\end{array}$ & $\begin{array}{l}22.8 \\
54.0 \\
13.0\end{array}$ \\
\hline INFO & $\begin{array}{l}\mathrm{NL} \\
\mathrm{HX} \\
\mathrm{ELD}\end{array}$ & $\begin{array}{l}19.7 \\
19.7 \\
17.3\end{array}$ & $\begin{array}{l}3.4 \\
2.9 \\
3.0\end{array}$ & $\begin{array}{l}14 \\
15 \\
13\end{array}$ & $\begin{array}{l}25 \\
24 \\
20\end{array}$ \\
\hline LEX DIV & $\begin{array}{l}\text { NL } \\
\mathrm{HX} \\
\text { ELD }\end{array}$ & $\begin{array}{l}41.2 \\
33.3 \\
35.8\end{array}$ & $\begin{array}{l}26.1 \\
17.2 \\
16.9\end{array}$ & $\begin{array}{l}16 \\
16 \\
15\end{array}$ & $\begin{array}{r}129 \\
102 \\
56\end{array}$ \\
\hline $\begin{array}{l}\text { COHESIVE } \\
\text { TIES }\end{array}$ & $\begin{array}{l}\mathrm{NL} \\
\mathrm{Hx} \\
\mathrm{ELD}\end{array}$ & $\begin{array}{l}89.1 \\
87.8 \\
82.3\end{array}$ & $\begin{array}{r}9.8 \\
12.4 \\
31.6\end{array}$ & $\begin{array}{l}68 \\
61 \\
35\end{array}$ & $\begin{array}{l}100 \\
100 \\
100\end{array}$ \\
\hline $\begin{array}{l}\text { NARRATIVE } \\
\text { STAGE }\end{array}$ & $\begin{array}{l}\mathrm{NL} \\
\mathrm{Hx} \\
\mathrm{ELD}\end{array}$ & $\begin{array}{l}4.2 \\
4.1 \\
4.3\end{array}$ & $\begin{array}{l}.69 \\
.58 \\
.50\end{array}$ & $\begin{array}{l}3 \\
3 \\
4\end{array}$ & $\begin{array}{l}5 \\
5 \\
5\end{array}$ \\
\hline
\end{tabular}


answer the research question.

Table IV displays the $P$ values for the one-way ANOVA's and the Duncan Test results for those variables which showed a significant difference at the .05 significance level. Table $\mathrm{V}$ shows the $\mathrm{P}$ values from the Kruskal-Wallis test and the results of the Mann Whitney $U$ pair wise comparisons.

No significant differences were found among the groups on the following measures: story length in T-units, typetoken ratio, average sentence length, information score, lexical diversity, cohesion, or narrative stage assignment. A significant difference was found among the groups on one measure only, mean length of utterance per T-unit.

\section{MLU per T-Unit}

A significant difference $(p<.05)$ was found among the groups. A Duncan Test showed that both the normal language group and the Hx group performed better than the ELD group. This indicates that ELD children used fewer morphemes per T-unit than normal language peers and children with a history of language delay who had moved into the normal range at second grade age. 
TABLE IV

ANOVA AND DUNCAN TEST RESULTS

\begin{tabular}{|c|c|c|c|c|}
\hline Variable & $\begin{array}{l}\text { ANOVA } \\
\mathrm{P}<.05\end{array}$ & $\begin{array}{c}\text { DUNCAN } \\
\text { NL }\end{array}$ & $\mathrm{Hx}$ & ELD \\
\hline \# T-units & .986 & NS & NS & NS \\
\hline MLU/T-Unit & $.017 *$ & 8.3 & 7.8 & 6.2 \\
\hline TTR & .428 & NS & NS & NS \\
\hline ASLS & .418 & NS & NS & NS \\
\hline Information & .342 & NS & NS & NS \\
\hline $\begin{array}{l}\text { Lexical Diversity } \\
\text { Unusual Word Types }\end{array}$ & .535 & NS & NS & NS \\
\hline $\begin{array}{l}\text { Cohesion } \\
\qquad \% \text { C Ties }\end{array}$ & .589 & NS & NS & NS \\
\hline $\begin{array}{r}\text { Narrative Stage } \\
\text { Assignment }\end{array}$ & .788 & NS & NS & NS \\
\hline
\end{tabular}

* - statistically significant

NS - statistically not significant 
TABLE V

KRUSKALL-WALLACE AND MANN WHITNEY U TEST RESULTS

\begin{tabular}{|c|c|c|c|c|}
\hline Variable & $\begin{array}{l}\text { KRUSKALL- } \\
\text { WALLACE }\end{array}$ & $\begin{array}{l}\text { MANN } \\
\text { WHITNEY U }\end{array}$ & N/ELD & $\mathrm{HX} / \mathrm{ELD}$ \\
\hline \# T-Units & .773 & NS & NS & NS \\
\hline MLU/T-UNIT & .022 * & $\mathrm{P}<. .05$ & .010 & .030 \\
\hline TTR & .548 & NS & NS & NS \\
\hline ASLS & .083 & NS & NS & NS \\
\hline Information & .478 & NS & NS & NS \\
\hline $\begin{array}{l}\text { Lexical Diversity } \\
\text { Unsual Word Types }\end{array}$ & .535 & NS & NS & NS \\
\hline $\begin{array}{l}\text { Cohesion } \\
\text { \& C Ties }\end{array}$ & .701 & NS & NS & NS \\
\hline $\begin{array}{r}\text { Narrative stage } \\
\text { Assignment }\end{array}$ & .760 & NS & NS & NS \\
\hline
\end{tabular}

* - statistically significant NS - statistically not significant 
DISCUSSION

These results indicate for those children who did not meet the criteria at age 20 to 34 months for normal expressive language, as defined by Rescorla (1989), 87\% present with language skills within the normal range for 7year olds by second grade, as measured by the DSS (Lee, $1974)$ scoring of their spontaneous language samples. The data collected to answer the research question regarding the performances of three groups with differing rates of language development shows that on a spontaneous story telling task, using a wordless picture book, no significant differences were found on measures of story length in T-units, TTR, average sentence length in morphemes, information, lexical diversity, cohesion, or narrative stage. The fact that these scores did not indicate any significant differences among the three groups may be attributed to the structure of the narrative task which supported the child's narration by providing pictures that depict the elements conforming to a story grammar. Also, the ELD group sample size during this examination was proportionately much smaller than in previous studies of these children. Therefore, there may not have been sufficient statistical power to make comparisons that would provide information from which we could draw strong 
conclusions.

The only significant difference found among the three groups was in the measure of mean length of utterance per T-unit. The normal language group and the history of language delay group performed significantly better than the children with chronic expressive language delay on this measure. This would suggest that utterances expressed by the children in the ELD group are syntactically less developed, as reflected on the DSS scores, which identified them as chronic in expressive language development at second grade age. However, measures which reflect semantic abilities, such as the information score, TTR, lexical diversity and narrative stage assignment, show that the ELD children have moved into a range which is not significantly different from their NL and $\mathrm{Hx}$ peers.

In 1991, Smith's study of these children at age 4 showed significant differences among the same three groups in several areas of narrative performance, i.e. in areas which reflected both semantic and syntactic abilities. MCFarland's (1992) study of these children during kindergarten showed that those children who had moved into the Hx group (due to their scores on the DSS, Lee, 1974), scored significantly higher than those who retained delays (ELD) on measures of cohesion and narrative stage assignment, but continued to score below their normal 
language peers on the lexical diversity score. The ELD group performed more poorly than the $\mathrm{NL}$ group on the score of lexical diversity, and they performed more poorly than both the $\mathrm{NL}$ and the Hx groups on measures for cohesion and narrative stage.

By first grade, as indicated by Johnson's (1993) study, the NL and Hx groups were significantly higher than the ELD group in terms of average sentence length, suggesting that the $\mathrm{NL}$ and $\mathrm{Hx}$ groups used more complex sentence structures than the ELD children. The $\mathrm{Hx}$ and the ELD children continued to show significantly lower scores than the NL group on the measure of narrative stage assignment during first grade, which suggests that the $\mathrm{Hx}$ and ELD children presented a lower level of maturity level in their narrative production. By second grade the ELD children continue to show lower ability in syntactic skills, as shown by the significantly poorer score for MLU per T-unit, although the average sentence length scores fell within the normal range, (the inverse of the first grade results). The improved average sentence length scores indicate the these children have increased their use of complex sentence structures, but due to the low MLU per T-unit scores, they may still be using shorter overall utterances per T-unit. These findings may suggest that the ELD children's overall output of language is shorter than 
those children with normal and history of late developing language.

There are some considerations as to why this trend may be evident. Scott (1988) discussed that MLU per T-unit increases throughout the school years, however, very slowly. The DSS scores at second grade level established that the ELD children performed more poorly than their peers in overall sentence structure. The MLU per T-unit score continues to reflect that these children have lower verbal output and produce shorter sentences than the NL and Hx children who scored 8.11 or above (10th percentile for age 6.6$)$.

Another consideration is that by second grade the majority of the children who were originally part of the late-talking group had moved into the Hx group, leaving only four children in the ELD group. Such a small sample size does not contribute a sufficient amount of statistical power to assume any broad-based conclusions. 
CHAPTER V

SUMMARY AND IMPLICATIONS

SUMMARY

Current research has shown that narrative tasks are indicative of later academic success in school age children (Roth \& Spekman, 1991; Westby, 1991). Other studies suggest narrative skill to be the best predictor for normal speech and language development for language impaired preschoolers (Bishop \& Edmundson, 1987). Narrative production involves extended units of text which present purpose, relevant information, attention to the listener's perspective, and the ability to make necessary repairs (Roth \& Spekman, 1991)

The purpose of this study was to examine the narratives produced by second grade children with different language histories and determine if significant differences exist among the three diagnostic groups. The original group size was 26 children with normal expressive vocabulary size at age 20 - 34 months, as reported on the Language Development Survey (Rescorla, 1989), and 30 children whose reported expressive vocabulary size fell below the normal range at 20 - 34 months, referred to as "late talkers". 
These two groups of children were re-examined when in the second grade at approximately age 7 . Each child was audiotaped producing a spontaneous conversational sample and a narrative using a wordless picture book.

Conversational language samples of all the children were scored for syntactic complexity according to the DSS (Lee, 1974). Twenty-four (87\%) of the original "latetalkers" had scores in the normal range and were reclassified as "history of Expressive Language Delay" $(\mathrm{Hx})$. The remaining four (138) who continued to fall below the normal range were now classified as "chronic in Expressive Language Delay" (ELD). Narratives produced by all the children were scored on eight measures: Mean Length of Utterance per T-Unit, Type-Token Ratio, Lexical Diversity, Narration Length in T-Units, Information Score, Average Sentence Length in Morphemes, Cohesion Adequacy, and Narrative Stage Assignment.

The data was analyzed to see if significant differences exist among the language diagnostic groups. In the event that the ANOVA measure found a significant $P$ value $(\mathrm{p}<.05)$, a Duncan Test was done to determine where the significant difference existed among the groups.

No significant differences were found among the three diagnostic groups on the following seven measures: TypeToken Ratio, Lexical Diversity, Narration Length in T- 
Units, Information Score, Average Sentence Length in Morphemes, Cohesion Adequacy, and Narrative Stage Assignment.

Significant differences were found among the groups on the Mean Length of Utterance per T-Unit. Both the NL group and the Hx group performed significantly higher than the ELD group.

\section{IMPLICATIONS}

\section{$\underline{\text { Research }}$}

As indicated by these data, $87 \%$ of those children whose expressive language did not meet the criteria for normal language development at age 20-34 months, now at second grade age, demonstrate expressive language skills within the normal range for 7-year olds, as measured on the DSS (Lee, 1974).

Paul \& Smith (1993) reported information on this group of children at age 4 . Their research data found that more than half (57\%) of the "late-talkers" at age 4 continued to present with impaired language skills. However, by second grade, all but four (878), of them had achieved scores in the normal range of expressive language production. The children who did not meet criteria were deficient in one area only, MLU per T-unit, indicating that although they 
are using fewer morphemes per T-unit utterance, they have caught up to their peers in the areas of semantic expression. As mentioned earlier, due to the small size of the ELD group by second grade, it is difficult to say that these children have really "caught up." The small sample size may make it difficult to measure statistically significant differences.

Although only one area (MUU/T-Unit) presented a statistically significant difference in scores, other scores that showed evidence of the normal talking children's scores being highest among the three groups were Type-Token Ratio (TTR), lexical diversity, and cohesive ties. These scores reflected the highest scores among the subjects in the normal group, and the lowest among the ELD children, while the $\mathrm{Hx}$ group means fell in between. On the score for information, the normal and Hx groups were equal while the ELD mean reflected the smaller score.

Future research of interest would be to re-examine these children through the remainder of elementary school and possibly into middle school. Scarborough and Dobrich (1990) describe a second spurt of language development post second grade, and Paul (1995) used the term “language for learning stage" to describe the development years between five to ten years of age or kindergarten through fifth grade. During these elementary school years oral language 
is the basis by which information is conveyed to children and the medium through which children demonstrate what they have learned. Paul (1995) describes three elements of language skill essential to the school aged child's academic success: classroom discourse rules, decontextualized language and metalinguistic skills. Gerber (1993) indicated that low syntactic skills may be an indicator of language learning disability. She reported that although children with LLD presented basic, functional syntactic ability, their sentences were not as well elaborated as those of school aged peers, and that relevant information was not always included in their utterances. The low expressive output of the ELD second graders may be an indication that these children are at risk for language learning disabilities which may affect the way they encode information in the academic setting. Future research investigating correlations between "late-talkers" at 20-34 months of age and post second grade academic performance, with emphasis on reading skills which would reflect the context in which the child's processing and encoding skills of language, are required.

\section{Clinical}

These findings suggest that children who by parent report on the LDS (Rescorla, 1989) used fewer than 50 words 
at age $20-34$ months outgrow their late start by the elementary school years. Deficits in narrative production, which depend on higher level language skills in children with early expressive language delay, tend to resolve, although syntactic skills in sentence structure as measured on the DSS (Lee, 1974) and total verbal output may continue to lag behind. Scott (1988) suggested that MLU per T-unit increases throughout the school years but very slowly. And between third and fifth grade increases in MLU per T-unit will be more apparent in written rather than spoken language. Further investigation beyond second grade of these children's use of syntax would be essential to determine if their lower verbal output is an indicator of later language learning problems. Paul (1995) recommends use of an "error analysis" to determine if language learning problems exist. Three aspects of the child's language production would be examined: 1. errors of morphology and syntactic form, 2. use of complex sentences and, 3. disruptions, such as false starts and excessive revisions.

These late talking children should continue to be monitored for difficulties which may arise in intermediate grades, as the format of classroom learning becomes more decontextualized. Children at this stage will need to be using language for learning as opposed to previous stages 
of learning language, in order to succeed academically (Paul, 1995). Although this study did not present large variances statistically among the groups, enough differences were evident to still be of concern for children as they enter the language for learning stages of their school years. Gerber (1993) suggests that there is no difference between comprehension of oral discourse and reading text material, as both tasks require linguistic knowledge about the content, form, and use of language. Therefore, a child with oral language limitations may present difficulty understanding meaning when confronting texts of written material.

Due to the small sample size of the groups, especially the ELD group, there was not sufficient statistical power to determine absolutely the degree of differences between the three groups. Since some differences were evident, even though they did not reach statistical significance, further investigation of these children's academic performance in their school years is warranted.

Looking at the children involved in this study over time, we saw in McFarland's (1992) and Johnson's (1993) studies investigations that those children who started out as late talkers at age 2 , gradually moved into the normal range, and that the gap between normal and late-talking children slowly closed. On first analysis it might seem 
then that early language intervention is not indicated since the problem appears to resolve itself by second grade. However, as discussed earlier, language is a symbolic medium by which information and communication is expressed and received, and provides the foundation upon which literacy will be formed. As children progress into the third and fourth grades, what Paul (1995) describes as the "language for learning stage", phonological awareness and metalinguistic abilities will be necessary to the young student's mastery of information presented in academic texts. If language development is the weak link in the chain, then it may reappear when this area is "stressed" at the language for learning stage. Therefore, children who started out in the normal talking group may move ahead of those who had a late start in expressive language. As an indicator for early language intervention, providing strategies at an early age (by kindergarten) may provide a boost and better prepare them to move into the language for learning stage as elementary school progresses.

As discussed previously, production of narratives relies on higher level language skills closely associated with reading and academic success. Therefore, many researchers feel the study of children's narratives to be a good indicator of later academic success (Mandler, 1982; Feagans \& Applebaum, 1986; Merrit \& Liles, 1987; Roth \& 
Spekman, 1989). Because of this strong connection between narrative ability and academic success, it continues to be important to assess narrative ability in school children with a history of language delay since these children may be at risk for later learning problems in the educational setting. Evaluation of narrative skills at early school age will help identify children who may be at risk for language learning disorders and will help predict how great the risk is for them. 
REFERENCES

Applebee, A. N. (1978). The Child's concept of story: Ages two to seventeen. Chicago: University of Chicago Press.

Bayley, N. (1969). Scales of infant development. New York: Psychological Corporation.

Bernstein, D. K. \& Tiegerman, E. (1989). Language and communication disorders in children (2nd Ed.). Columbus, Ohio: Merrill Publishing.

Bishop, D. V. M. \& Edmundson, A. (1987). Language-impaired 4-year olds: Distinguishing transient from persistent impairment. Journal of Speech \& Hearing Disorders, 52, 156-173.

Donahue, M. (1986). Linguistic and Communication development in learning children. In S. Ceci (Ed.), Handbook of cognitive, social, and neuropsychological aspects of learning disabilities, 263-289. Hillsdale, NJ: Erlbaum.

Dunn, L. M. \& Markwardt, F. C. (1970). Peabody Individual Achievement Test (PIAT). Circle Pines, MN: American Guidance Service.

Feagans, L. \& Applebaum, M.I. (1986). Validation of language subtypes in learning disabled children. Journal of Educational Psychology, 78, 358-364.

Flood, J. \& Lapp, D. (1987). Reading and writing relations: Assumptions and directions. In J. Squire (Ed.), The dynamics of language learning. Urbana, IL: ERIC.

Gerber, A. (1993). Lanquage-related Learning Disabilities: Their Nature and Treatment. Baltimore: Paul H. Brooks.

Guilford, J. P. (1954). Psychometric Methods. New York: McGraw Hill.

Halliday, M.A. K. \& Hasan, R. (1976). Cohesion in English. London: Longman Group Limited.

Harris D. (1963). Children's drawings as a measure of 
intellectual maturity. A revision and extension of the Goodenough Draw-A-Man Test.

Hollingshead, A. (1975). Four factor index of social status. New Haven, University.

Hunt, K. (1965). Grammatical structure written at three grade levels (Research Report No. 3). Champaign, IL: National Council of Teachers of English.

Johnson, K. E. (1993). A study of the narrative skills in 6-year olds with normal, impaired and late developing language. Unpublished master's thesis, Portland State University, Portland, OR.

Kamhi, A. G. and Lee, R. F. (1988). Cognition (Chapter 6) . In M. Nippold, (Ed.), Later language development: Ages 9 through 19 (pp. 127-158). Boston: Little, Brown \& Co.

Kinitch, w. (1977). On comprehending stories. In E. Just \& A. Carpenter (Eds.), Cognitive process in comprehension (pp. 33-62). Hillsdale, NJ: Colbanar.

Lee, L. (1974). Developmental sentence analysis. Evanston, IL: Northwestern University Press.

Levi, G., Musatti, L, Piredda, L. Sechi, E. (1984). Cognitive and linguistic strategies in children with reading disabilities in an oral storytelling test. Journal of Learning Disabilities, 17, 406-410.

Liles, B. Z. (1985). Cohesion in the narratives of normal and language disordered children. Journal of Speech and Hearing Research, 28, 123-133.

Liles, B. Z . (1987). Episode organization and cohesive conjunctives in narratives of children with and without language disorder. Journal of speech and Hearing Research, 30, 185-196.

Lindamood, C. H. \& Lindamood, P. C. (1979). Lindamood Auditory Conceptualization Test (LAC). TX: DLM Teaching Resources.

Loban, w. D. (1963). The lanquage of elementary school children. No. 1 in a series of research reports sponsored by the NCTE Committee on Research. Urbana, IL: National Council of Teachers of English. 
Mandler, J. M. \& Johnson, N. S. (1977). Remembrance of things passed: Story structure and recall. Cognitive Psychology, 9, 111-151.

Maxwell, J. (1977). Reading progress from 8 to 15 . Windsor, Great Britain: NFER Publishing.

Meyer, M. (1967). A Boy, A Dog, and A Frog. New York: Dial Books For Young Readers.

McCarthy, D. (1972). McCarthy Scales of Children's Abilities. Ohio: The Psychological Corporation.

MCFarland, L. L. (1992). A study of the narrative skills in kindergarten children with normal, impaired, and late developing lanquaqe development. Unpublished master's thesis, Portland State University, Portland, OR.

Merritt, D.D. \& Liles, B. Z. (1987). Story grammar ability in children with and without language disorder: Story generation, story retelling and story comprehension. Journal of Speech \& Hearing Research, 30, 539-552.

Miller, J. F. (1981). Assessing language production in children: Experimental procedures. Baltimore: University Park Press.

Nelson, N. W. (1988). Reading and writing. In Nippold (Ed), Later lanquage development. (pp. 97-125) Austin, Tx: Pro-Ed.

Miller, J.F. (1981). Assessing language production in children: Experimental procedures. Baltimore: University Park Press.

Miller, J. R. \& Chapman, R. (1985). Systematic analysis of language transcripts: User's manual. Madison, WI: University of Wisconsin.

Newcomer \& Hammill, D. D. (1988). Test of Lanquage Development Primary (TOLD-2). Austin, Texas: Pro-Ed.

Nockerts, A. (1991). Lexical Richness Computer Program, Oshkosh: WI.

Paul, R. (1995). Lanquage Disorders From Infancy Through Adolescence. St. Louis: Mosby-Year Book Inc.

Paul, R. \& Riback, M. (1993). Sentence structure development in late talkers. Poster session presented 
at the Symposium for Research in Child Language Disorders, Madison, WI.

Paul, R. \& Smith, R.L. (1993). Narrative skills in 4-year olds with normal, impaired, and late developing language. Journal of Speech and Hearing Research, 36, 592-598.

Pitcher, E. G. \& Prelinger, E. (1963). Children tell stories: An analysis of fantasy. New York: International Universities Press.

Rescorla, L. (1989). The language development survey: a screening tool for delayed language in toddlers. Journal of Speech \& Hearing Disorders, 54, 587-599.

Renfrew, C. E. (1977). The Bus Story: A test of Continuous speech. Old Headington, Oxford, England: Author.

Roth, F. P. \& Spekman, N. J. (1986). Narrative discourse: Spontaneously generated stories of learning-disabled and normally achieving students. Journal of Speech \& Hearing Disorders, 51, 8-23.

Roth, F. P. \& Spekman, N. J. (1989). The oral syntactic proficiency of learning disabled students: A spontaneous story sampling analysis. Journal of Speech and Hearing Research, 32, 67-77.

Roth, F. P. \& Spekman, N. J. (1991). Higher-order language processes and reading disabilities. In A. G. Kamhi \& H. W. Catts (Eds.), Reading disabilities: A developmental language perspective (pp. 159-188). Needham Heights, MA: Allyn and Bacon.

Rumelhart, D. E. (1975). Notes on a schema for stories. In D. G. Bobrow \& A. M. Collins (Eds.), Representation and understanding: Studies in cognitive science ( $\mathrm{pp}$. 265 - 303). New York: Academic Press.

Scarborough, H. S. \& Dobrich, W. (1990). Development of children with early language delay. Journal of speech and Hearing Research, 33, 70-83.

Scott, C. M. (1988). A perspective on the evaluation of school children's narratives. Lanquage Speech \& Hearing Services in Schools, 19, 67-82.

Sparrow, S. S., Balla, D. A., Cicchetti, D. V. (1984). 
Vineland Adaptive Behavior Scales. Circle Pines, MN: American Guidance Service.

Stein, N. \& Glenn, C. (1979). An analysis of story comprehension in elementary school children. In R.O. Freedle (Ed.), New direction in discourse processing (Vol. 2) (pp. 53-120). Norwood, NJ: Ablex.

Stephens, M. I. (1988). Pragmatics (chapter 11). In M. Nippold, (Ed.), Later language development: Ages 9 through 19 (pp. 247-262). Boston: Little, Brown \& Co.

Vygotsky, L. S. (1962). Lanquage and thought. Cambridge, MA: MIT Press. (Original work published 1934).

Wepman, J. M. \& Hass, W. (1969). A spoken word count. Chicago: Language Resource Assoc.

Warner, W. L., Meeker, M., \& Eells, K. (1949). Social class in America. Chicago: Science Research Associates.

Westby, C. (1985). Learning to talk-talking to learn: Oral-literate language differences. In C. Simon (Ed.), Communication skills and classroom success: Therapy methodologies for lanquage learning disabled students. San Diego, CA: College-Hill Press.

Westby, C. (1991). Assessing and remediating text comprehension problems. In A. G. Kamhi \& H. W. Catts (Eds.), Reading disabilities: A developmental lanquage perspective (pp. 199-250). Needham Heights, MA: Allyn and Bacon.

Whiteman, M. F. (Ed.) . (1981). Writing: The nature development and teaching of written communication: (Vol 1), Variation in writing: Functional and linguistic-cultural differences. Hillsdale, $\mathrm{N} J$ : Erlbaum. 
APPENDIX A

HUMAN SUBJECTS RESEARCH FORM 


\section{OFFICE OF GRADUATE STUDIES AND RESEARCH}

DATE: $\quad$ December $9 \mathrm{th}, 1994$

TO: $\quad$ Rita Hernandez

Social Security: 046-50-6214

FROM: $\quad \begin{aligned} & \text { HSRRC Waived Review of Your Application titled "A Study of the Narrative } \\ & \text { Skills of 7-Year Olds with Normal, Impaired, and Late Developing Language" }\end{aligned}$

Your proposal is exempt from further HSRRC review, and you may proceed with the study.

Even with the exemption above, it was necessary by University policy for you to notify this Committee of the proposed research and we appreciate your timely attention to this matter. If you make changes in your research protocol or if data collection continues over a year from the above date, the Committee must be notified.

\section{c. Maureen Orr Eldred Project Advisor}


APPENDIX B

QUESTIONNAIRE FOR PARENTS OF

CHILDREN 15 - 30 MONTHS OLD 
QUESTIONNAIRE FOR PARENTS OF CHILDREN 15-30 MONTHS OLD

What is your child's:

first name?

date of birth?

Mother's (or primary parent's) full name?

Mother's (or primary parent's) phone number?

Mother's occupation

Father's occupation

How many different words can your child say? (It's oK if the words aren't entirely clear, as long as you can understand them).

none

less than five

$10-30$

5-10

$30-50$

more than 50

If your child says fewer than ten words, please list them here:

Does your child put words together to form short "sentences"?

Yes No

If yes, please give three examples here:

Would you be interested in participating in later parts of this study?

Yes

No 
APPENDIX C

OREGONIAN ARTICLE 


\section{Toddlers with delayed speech sought}

A Portland State University researcher is looking for otherwise normal toddlers who begin talking late to serve as subjects in a study of delayed speech and its connection, if any, to later language problems.

Rhea Paul, a PSU assistant professor of speech communication, said the reasons for delayed speech in "late-blooming" young children and the early identification of toddlers who later will suffer chronic language delay had not been well-investigated, although perhaps 10 percent of American children may fall into those categories.

Paul is interested in srudying children between the ages of 18 and 30 months in the Portland-Vancouver area who can say only five or fewer words, instead of the 50 or so most children can speak by that age. She hopes to monitor their progress in speech development for two to five years, using such tools as speech tests and videotaped play sessions with their parents, to determine whether the children are indeed late-bloomers or whether their lack of early communication skills signals the start of severe speech and language delays.

Early identification of such children may allow early intervention and prevent future speech deficits, she said.

Paul's research is funded by the Fred Meyer Charitable Trust, the American Speech, Language and Hearing Foundation, and PSU. Parents who are interested in allowing their children to participate may contact Paul through the PSU Department of Speech.

The Oregonian, Portland, Oregon 
APPENDIX D

LANGUAGE DEVELOPMENT SURVEY 
Rescorla: The Lunguake Developmen: Suriey

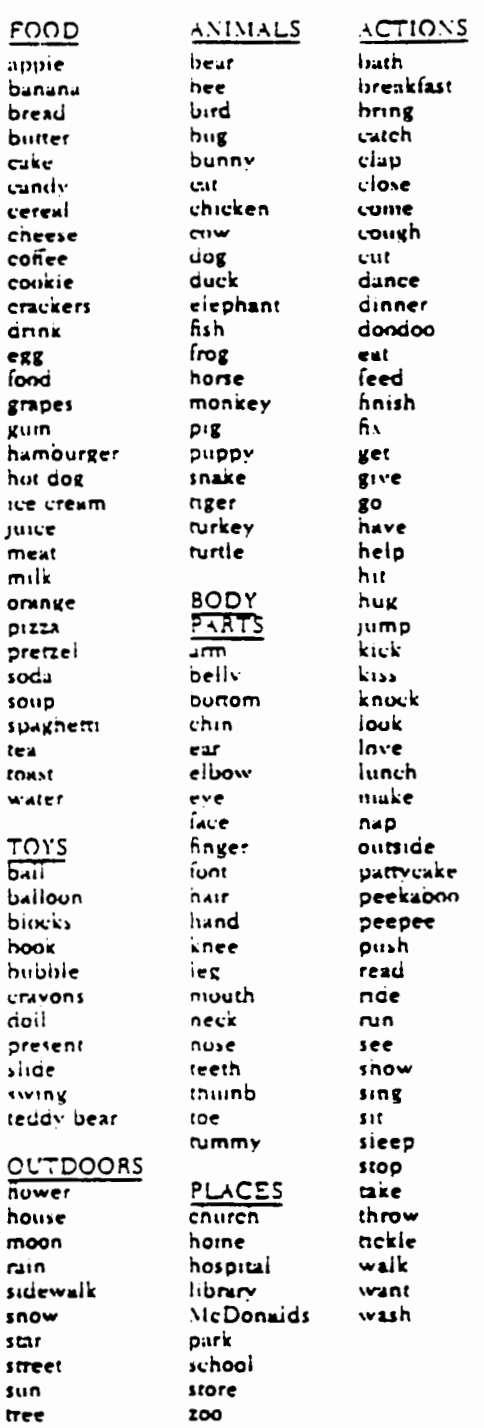

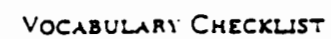

brush

cnnb

giasses kie:

money

paper

pen

pencil

penny:

pockiectbouk

nssue

toochbrush

umbrella

watch

PEOPLE

aunt

bub:

bor:

dacidy.

doctor

girl

grundina

grandpa

lad.

man

mommy

own name

pet name

uncie

Emie. etc.

\section{CLOTHES}

beit

boots

coat

dress

hloves

jacket
mittens

mitens

pasumus

shirt

shoes

slippers

sneaicers

socks

sweater

VEHICLES

bike

boal

bus

car

motorbike

plane

stoller

oxin

trolley

rruck

MODIFIERS
allgone
all nght
bed

bed

bis

black

blue

broken

cters

dark

down

good

happy

heavy

hot

hungry

linte

mine

more

open

pretry

red

shue

sanity

that

this

nred

up

wet

winte
veilow

vucixy.
OTHERS

A. B. C. ere.

away

booboo

brebre

curse wonds

here

hi. hello

in

me

meow

my.

nivseif

nightnichs

of

E

ou

please

Sesame St

scuse me

shut up

thank rou

there

uncer

weicome

what

where

why

woofiroof

yes

you

yumyum

1. 2. J. esc.

Please lise anv other woros vour child uses here:

Does vour child combine wo op more words in phrases?

(e.s.. more cookie. car buebye. etc.) yes

no

Please list beiou THREE of your child's longest and best sentences or phrases.

This suney instrument was developed by Lestie Rescoria. Ph.D 


\author{
APPENDIX E \\ DEVELOPMENTAL SENTENCE SCORE: \\ SCORING CRITERIA
}

Lee, L. (1974) Developmental sentence analysis.

Evanston, IL: Northwestern University Press. 


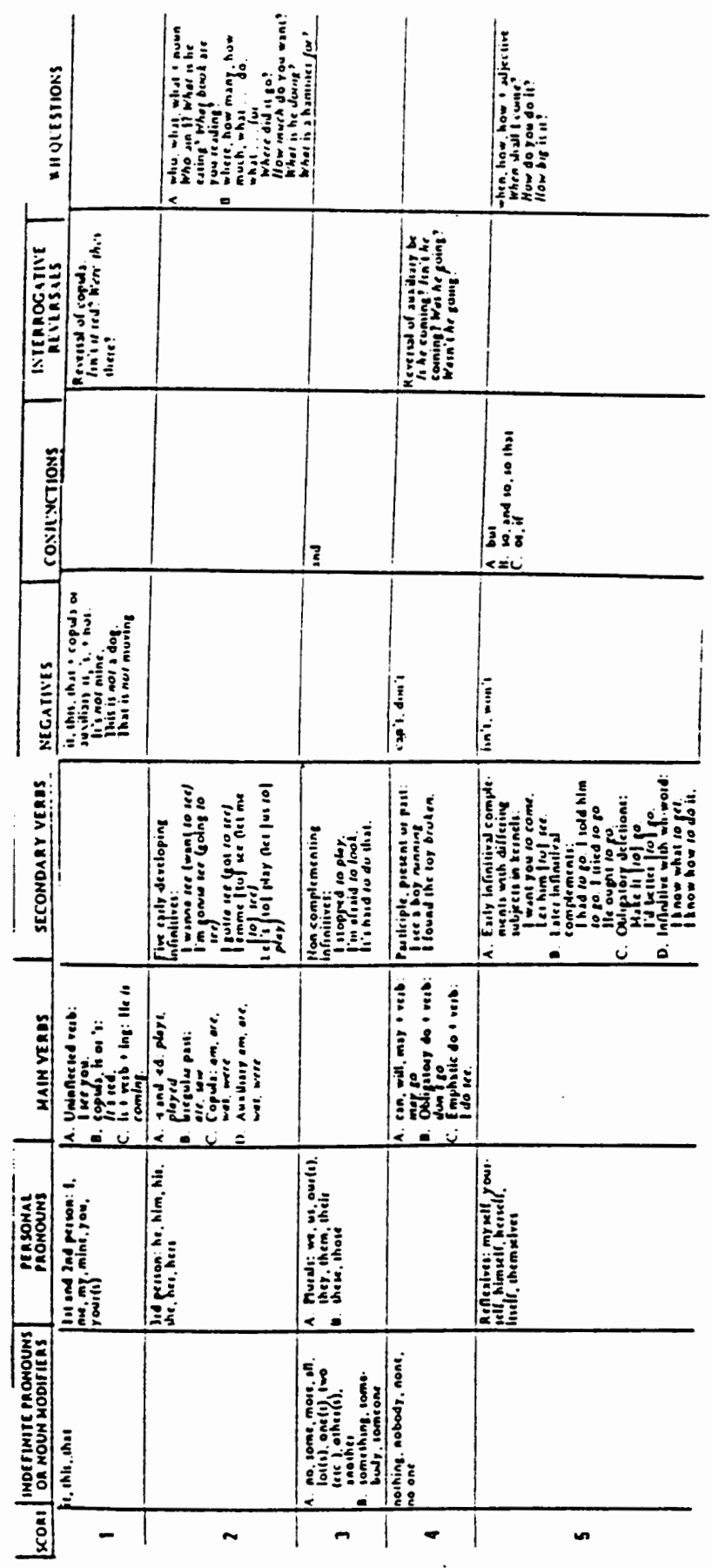




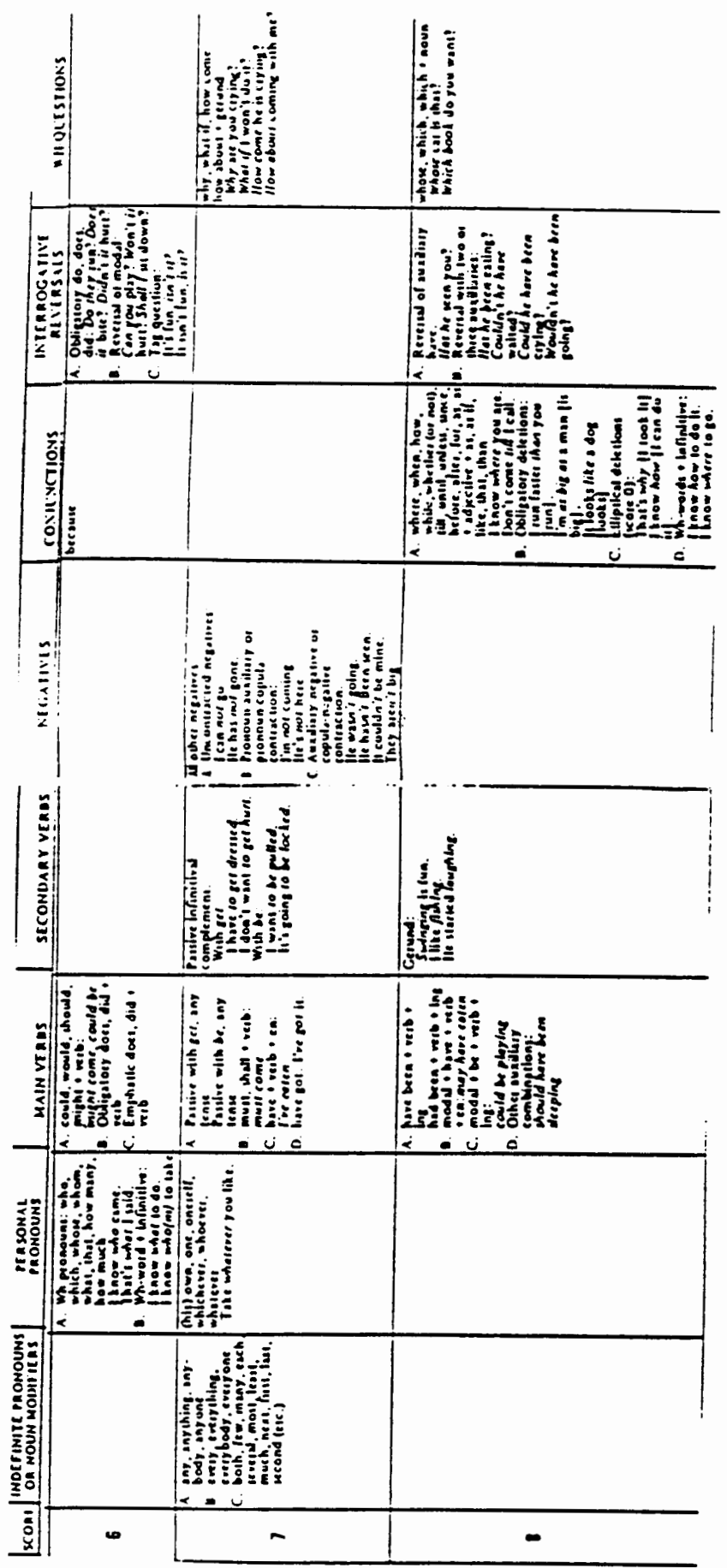




\section{APPENDIX F}

\section{DEVELOPMENTAL SENTENCE SCORE:}

\section{NORMS}

Source: Lee, L. (1974). Developmental sentence

analysis. Evanston, Il: Northwestern University Press. 
Figure 1. Norms for Deveiopmental Sentence Scoring (Reweighted)

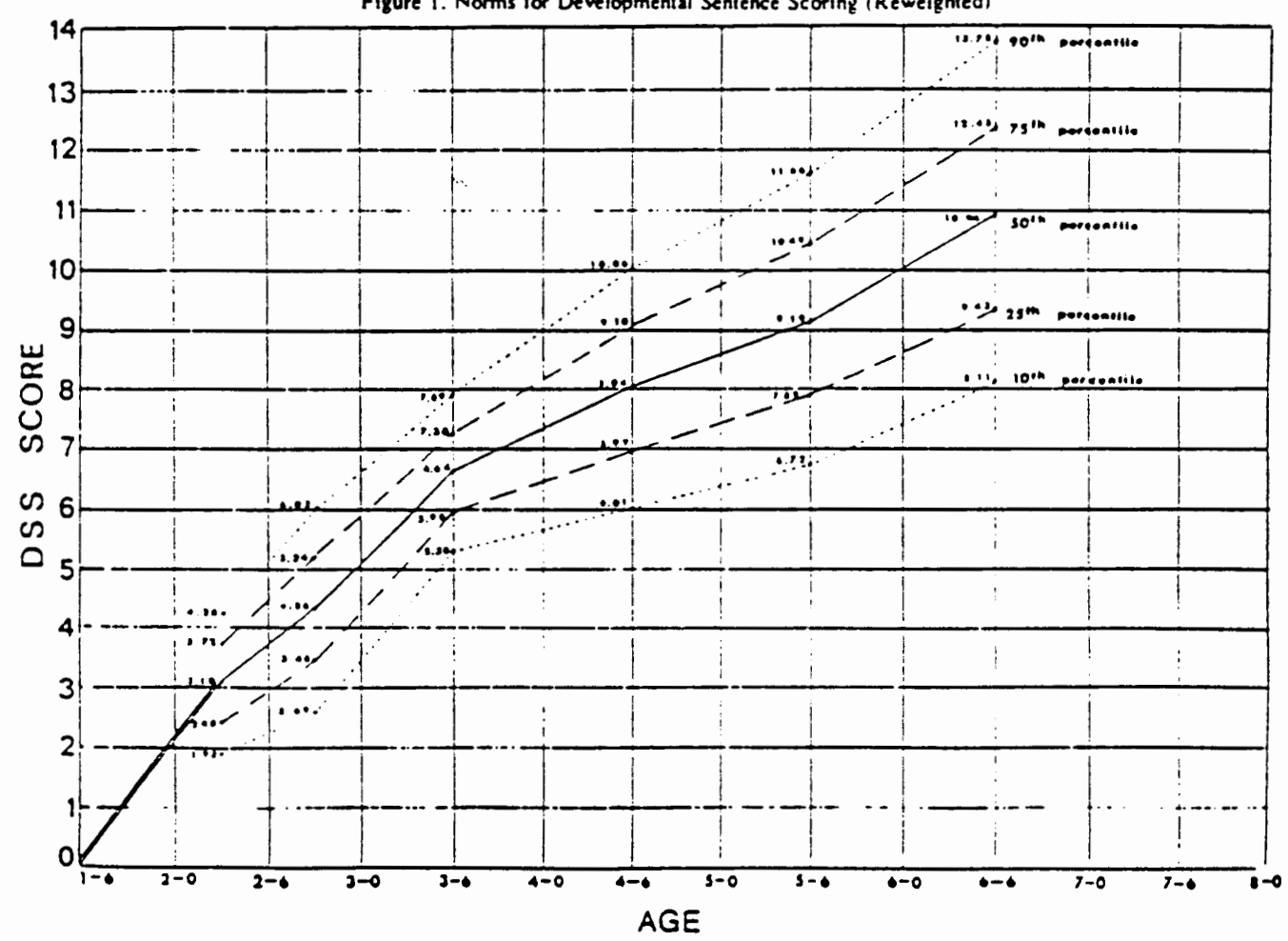


APPENDIX G

NARRATIVE ANALYSIS CRITERIA

Source: adapted from the work of Applebee (1978), KlecanAker \& Kelty (1990), Klecan-Aker, Mcingvale \& Swank (1987), McFarland (1992), and Stein \& Glenn (1979). 
NARRATIVE SCORING PROCEDURE

1) Heap

2) Sequence

3) Primitive Narrative

4) Chain

5) True Narrative
Stories where children are labeling and/or describing events or actions. There is no cerebral theme.

Labeling or describing events about a central theme.

Contains the three story grammar components of $A$ ) initiating event, B) attempt or action and $C$ )

consequences around a central theme.

Four story grammar components: initiating event, attempt or actio, consequence, and character motivation or internal response. There may be an ending but it's abrupt.

Contains at least 5 story grammar components, three of which are initiating event, attempt or action and consequence. The ending indicates a resolution of the problem. 


\section{APPENDIX H}

RULES FOR COUNTING T-UNITS AND WORDS

Source: Strong, C. \& Shaver, J. (1991). Stability of cohesion in the spoken narratives of language-impaired and normally developing school-aged children. Journal of Speech and Hearing Research, 34, 95-111. 
RULES FOR COUNTING T-UNITS AND WORDS

The following rules were used for dividing the narratives T-units and for counting the number of words in each $\mathrm{T}$ -

Exact repetitions of words or phrases were not counted. Syntactic and/or semantic revisions that did not have a complete thought were not counted.

T-units were included even if not grammatically correct. Direct quotations that completed a verb phrase were not considered as a separate $\mathrm{T}$-unit.

sentence fragments were counted when utterance final intonation contours clearly indicated that a complete thought had been spoken.

Unintelligible words or phrases were not counted. 


\section{APPENDIX I}

\section{MOST COMMON WORDS \\ USED BY 6-YEAR OLDS}

Source: Wepman, J. \& Hass, W. (1969). A spoken word count. Chicago: Language Resource Association. 
500 MOST COMMON WORDS USED BY 6 YEAR OIDS

\begin{tabular}{|c|c|c|c|}
\hline AND & HOUSE & TIME & VERY \\
\hline IS & MIGHT & THEIR & DARK \\
\hline THE & MOTHER & TREE & ANY \\
\hline $\mathrm{HE}$ & GIRL & PUT & ROCK \\
\hline A & WANT & KILI & HOW \\
\hline TO & GOT & REAL & BED \\
\hline IT & LITTLE & WORK & MAKE \\
\hline SHE & KNOW & PICTURE & ONCE \\
\hline THERE & WENT & DOOR & SLEEP \\
\hline THEY & HAVE & SAID & FIND \\
\hline THAT & IF & BIG & HAND \\
\hline WAS & DOWN & MEN & LOT \\
\hline LOOK & HAS & TWO & SCHOOL \\
\hline IN & JUST & SIT & WATCH \\
\hline THIS & WITH & FROM & OLD \\
\hline NOT & BUT & CAUSE & RUN \\
\hline MAN & FOR & PEOPLE & SNOW \\
\hline GO & WHAT & No & GOOD \\
\hline MAYBE & YOU & THESE & SAY \\
\hline THEN & DOES & INTO & HAIR \\
\hline WELL & WERE & HOME & NOW \\
\hline I & WHEN & NIGHT & BLACK \\
\hline HER & SEE & ROOM & CLIMB \\
\hline LIKE & WILL & TELL & WALL \\
\hline so & $B A C K$ & HORSE & AFTER \\
\hline HIS & OTHER & WATER & HAPPEN \\
\hline OF & PLAY & GUY & TALK \\
\hline ON & CAME & WHERE & HOLD \\
\hline OR & ABOUT & BOOK & DIE \\
\hline ARE & FATHER & AROUND & MEAN \\
\hline ALL & THEM & TAKE & NOTHING \\
\hline $\mathrm{AT}$ & DAY & CRY & MARRY \\
\hline HIM & HAD & MORE & HAPPY \\
\hline SOME & COULD & OVER & READ \\
\hline LADY & WOULD & LIGHT & AGAIN \\
\hline THINK & COME & KISS & MAD \\
\hline ONE & PROBABLY & SAW & BEEN \\
\hline GET & DID & ANOTHER & FOUND \\
\hline DO & BOAT & OPEN & ELSE \\
\hline UP & TRY & SOMEBODY & BABY \\
\hline OUT & THING & RIGHT & FISH \\
\hline $\mathrm{BE}$ & HERE & TOO & WAY \\
\hline SOMETHING & WINDOW & END & LET \\
\hline BOY & LIVE & $\mathrm{OH}$ & KIND-OF \\
\hline BECAUSE & AWAY & $B Y$ & ASLEEP \\
\hline CAN & WALK & HARD & ANYTHING \\
\hline
\end{tabular}




\begin{tabular}{|c|c|c|c|}
\hline EVERYTHING & STATUE & BEFORE & BRING \\
\hline OFF & $A M$ & LISTEN & STAR \\
\hline SOMEONE & PLANT & BRIDGE & PICK \\
\hline WHO & CALL & SHOT & RIDE \\
\hline SIDE & KID & HOT & BURY \\
\hline MADE & VIOLIN & TOGETHER & ANIMAL \\
\hline FALI & THROUGH & ALONG & STOP \\
\hline EAT & FRIEND & BROKE & NEW \\
\hline START & REALIY & FAST & WHATEVER \\
\hline WOMAN & EVER & EVEN & CABIN \\
\hline OUTSIDE & YEAR & STAIR & COAT \\
\hline LOVE & FIELD & LAMP & EXCEPT \\
\hline $\mathrm{ME}$ & RAN & JUMP & GONE \\
\hline AN & FIRE & LUNCH & SHOE \\
\hline NEXT & ASK & PAPER & SORT-OF \\
\hline WE & BEHIND & FOUR & $\mathrm{BOX}$ \\
\hline MONSTER & DOLL & KNIFE & OKAY \\
\hline ROPE & THOUGHT & STEP & YEAH \\
\hline SHOULD & NICE & HIMSELF & BUY \\
\hline MUCH & BETTER & BARN & PRAY \\
\hline HUSBAND & HEAD & MUST & WAR \\
\hline WAIT & SAD & US & CAVE \\
\hline WHITE & BRICK & MONEY & GAVE \\
\hline PIAACE & GUESS & ALMOST & HOSPITAL \\
\hline FOOD & CHILD & CLOTHES & PAINTING \\
\hline TOOK & WONDER & ONLY & SHINE \\
\hline UPON & GIVE & FOREST & WEAR \\
\hline STORY & HURT & STUFF & GRANDMOTHER \\
\hline $\mathrm{EACH}$ & REST & MOUNTAIN & HILI \\
\hline GRASS & WOKE & LAY & INSTRUMENT \\
\hline KIND & HELP & FIVE & ARM \\
\hline DECIDE & FIX & SICK & PLOW \\
\hline BOTH & EYE & DANCE & EVERY \\
\hline MY & STAND & TIRED & SHUT \\
\hline LONG & NEVER & NEAR & PART \\
\hline STAY & GROUND & GARDEN & DAUGHTER \\
\hline GUN & THREE & MOVE & FIRST \\
\hline BUG & GROW & YES & EVERYBODY \\
\hline CHILDREN & TOP & FEEL & INSIDE \\
\hline DEAD & UNTIL & HEARD & COAL \\
\hline WIFE & CAR & DAD & CORN \\
\hline SOMEWHERE & DOG & STONE & AS \\
\hline LEFT & FIGHT & READY & WOOD \\
\hline FELL & KEPT & TURTLE & BROKEN \\
\hline GRAVE & TABLE & LAKE & DONE \\
\hline TURN & HAPPILY & POLICE & GUITAR \\
\hline MORNING & KEEP & FACE & $\mathrm{HIGH}$ \\
\hline $\mathrm{BAD}$ & THOSE & TOLD & HARDLY \\
\hline FLOWER & WRONG & BLANK & PIECE \\
\hline PRETTY & STORE & OWN & GREAT \\
\hline UNDER & FARM & PAINT & PULI \\
\hline WHILE & SWIM & HAT & THOUSAND \\
\hline
\end{tabular}




\begin{tabular}{|c|c|c|}
\hline FLOOR & HERSELF & WOLF \\
\hline WINTER & LINE & HAY \\
\hline COUNTRY & SNAKE & MOUSTACHE \\
\hline RIVER & STORM & \\
\hline DOCTOR & TORNADO & \\
\hline ATE & BAG & \\
\hline SISTER & COLD & \\
\hline BURN & WON & \\
\hline BROTHER & SEA & \\
\hline CHOP & TIE & \\
\hline SAII & CARD & \\
\hline HOLE & FORGOT & \\
\hline ARMY & USE & \\
\hline CATCH & EVERYONE & \\
\hline SUMMER & YOUR & \\
\hline MOM & LEAF & \\
\hline WAKE & CUT & \\
\hline AGAINST & HUNDRED & \\
\hline CAUGHT & LOG & \\
\hline LAND & MAY & \\
\hline ALREADY & ANT & \\
\hline $\mathrm{COUCH}$ & FINISH & \\
\hline CROSS & LESSON & \\
\hline EARLY & CASTLE & \\
\hline BEDROOM & CLEAN & \\
\hline BIRD & TUNE & \\
\hline NAME & CEMETERY & \\
\hline BURGLAR & DINOSAUR & \\
\hline GRANDFATHER & PRACTICE & \\
\hline BROUGHT & SOMEPLACE & \\
\hline ACROSS & CHAIR & \\
\hline CLOSE & STICK & \\
\hline RAIN & TEACH & \\
\hline SAME & FORGET & \\
\hline PAY & PET & \\
\hline CAT & SENT & \\
\hline GRANDMA & BOUGHT & \\
\hline SKY & CARE & \\
\hline WRECK & FUNNY & \\
\hline ANYBODY & TEN & \\
\hline DRY & SNOWY & \\
\hline ROBBER & STILL & \\
\hline KNOCK & SIX & \\
\hline SUN & SOON & \\
\hline COUPLE & BELOW & \\
\hline WHY & MINUTE & \\
\hline POND & $\mathrm{TV}$ & \\
\hline DEAR & GAME & \\
\hline BIT & SOMETIMES & \\
\hline SEED & BUMP & \\
\hline ALWAYS & FAINT & \\
\hline
\end{tabular}




\section{APPENDIX J}

COHESION SCORING PROCEDURE

Source: Liles, B. Z. (1985). Narrative ability in normal and language disordered children. Journal of Speech and Hearing Research, 28, 123-133. 


\section{PROCEDURE FOR THE IDENTIFICATION OF COHESIVE MARKERS}

In this procedure it is important that the examiner be familiar with the original story being told. First read the entire narrative to get an overall sense of the text. Then read each sentence separately as a complete unit before identifying those items in the sentence that mark cohesion.

At this stage in the procedure the examiner views each sentence as isolated from text. From this viewpoint the examiner judges an item to be a cohesive element or not under the following conditions.

1. Definition of cohesive marker. An element is identified as a cohesive marker if its meaning cannot be adequately interpreted by the 1 istener and if the listener must "search" outside that sentence for the completed meaning.

In addition, an element may be judged a cohesive element if it is used as a linguistic marker that leads the listener to "expect" that its interpretation is outside the sentence (e.g., definite articles). or lexical. Cohesive markers may be reference, conjunction,

2. Relationships within the sentence. Do not judge an item as a cohesive marker if the information referred to is recoverable within the sentence. The following are examples of information recovered within the sentence.

Some boys took their car home.

Personal reference their refers to boys; therefore, the information is recoverable within the sentence.

There was this scientist that had a hideout in these mountains where there was this radar tower to blow up metal things that $f l y$ in the air.

In the example above the information referred to by the use of this and these as selective demonstrative references (Halliday \& Hasan, 1976, p. 70) is recovered within the sentence. Thus, the examiner would not identify this or these as a cohesive marker (i.e., information recoverable outside the sentence).

The next example demonstrates a cohesive and a noncohesive marker in the same sentence. 
One of the boys went home.

The demonstrative reference the marks which or what boys, and serves as a cue to the Iistener that the information is recoverable outside the sentence and is, therefore, cohesive. However, one refers within the sentence to boys and is not a cohesive marker.

3. Text influence on judgement. Although this procedure calls for the examiner to view each sentence as independent from the text when identifying cohesive markers, there are instances when the text must be considered. For example, in the sentence,

Marie didn't want to go on the hike.

the listener may need more information about Marie in order to comprehend the text. In this particular text, the listener would ask, "Who is Marie?"

Thus the decision as to whether a particular item is a cohesive marker or not is "text dependent." As texts vary specific items may vary in their cohesive function.

(a) Text influence on demonstrative reference. While the is a selective demonstrative reference, it may also be used in combination with words to express a unit of meaning (e.g., "the road," "the radio," "the newspaper"). It may be difficult to determine when the speaker intends the as a selective demonstrative reference or if the is used as an uninflected functor. To make this judgement, the examiner must take the text into consideration. For example, if the speaker used "the road" and the examiner judges that reference to a particular road is important within the text, he/she judge that the speaker intended the to be used as selective reference and would identify it as a cohesive marker. The following rule will facilitate judgement:

If in doubt about the use of because of the above reasons, do not code the as a selective demonstrative reference if a or some can be substituted without producing a crucial change in the meaning of the text.

4. Two or more cohesive markers within a sentence.

(a) Conjunctions. When two or more conjunctions (e.g., and then or and so then) are conjoined $n$ a 
sentence code only one of the conjunctions as a cohesive item. Select the conjunction that is the most complex according to the following hierarchy: (a) Causal, (2) Adversative, (3) Temporal, (4) Additive.

(b) Reference: Demonstrative and comparative. When both a demonstrative and comparative reference are used (e.g., the other) code only as one cohesive item (comparative) rather than as two items (demonstrative and comparative).

(c) Reference: Personal and demonstrative. If two or more references (i.e., either personal or demonstrative) are judged to be cohesive in the same sentence, code all markers even though they refer to a common reference, for example:

He took his comic books home.

Although the sentence structure indicated that his refers within the sentence to he, there is not lexical support within the sentence to provide the listener with the information needed to know to whom his refers. Therefore, he and his are both cohesive.

After the examiner has identified the cohesive markers within each sentence according to the procedure presented above, he/she then reread the sentence with a different perspective. The makers that had been identified as cohesive are now viewed as part of the text.

PROCEDURE FOR THE IDENTIFICATION OF COHESIVE ADEQUACY

1. Complete tie. A tie is complete if the information referred to by the cohesive marker is easily found and defined with no ambiguity.

2. Noncomplete tie. A tie is judged to be noncomplete if: (a) the information referred to by the cohesive maker is not provided in the text, for example,

Two boys went to see a movie.

They saw his car parked in front.

In this example, the speaker had not provided the information (i.e., whose car?) but instead the personal reference his, cueing the listener to recover the information outside the 
sentence.

(b) the listener is guided to ambiguous information, for example,

Homer and Freddie went to the movie. He enjoyed it very much.

In this case the listener would not know which boy enjoyed the movie.

Conjunctions are a special case of cohesive tying. All conjunctions that are not completely adequate are judged to be errors (or noncomplete). Accordingly, if the ideas or messages presented in the two conjoined sentences are unrelated or inappropriately sequenced, the conjunction used to join the ideas is judged to be noncomplete.

Further criteria for cohesion scoring (outlined by this investigator:

1. Sentences are total utterances, not T-units.

2. Use the information provided in false starts.

3. Do not count initial ands as conjunctions.

4. After doing worksheet, count up all the complete and noncomplete ties.

5. The raw score for each narratives the total number of complete ties.

6. The frequency is the percentage of complete ties used in the narrative. Divide the number of complete ties by the number of noncomplete ties. 
Cohesion Worksheet:

Cohesive
Marker
line\#/item
complete/noncomplete

Tied to

info in

line\#/item
Marker

judgment

TOTAL COMPLETE

TOTAL NONCOMPLETE

$=$ $\%$ OF COMPLETE

TIES

+ TOTAL COMPLETE 
APPENDIX K

INFORMATION SCORE CRITERIA 
SCORING FOR INFORMATION

Read the whole narrative. Go back and read the narrative, giving one point for each idea forming an essential part of
the story.

Score only those ideas listed below.

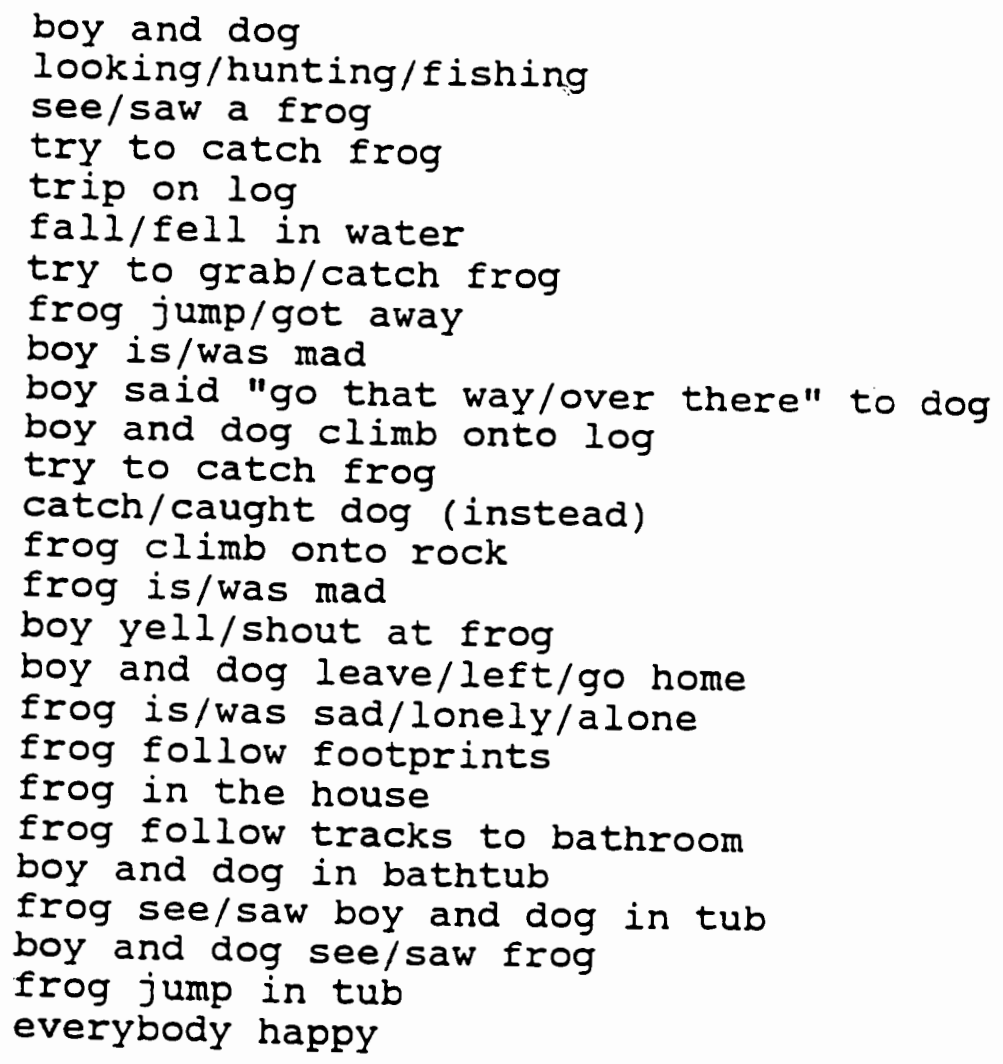

